\title{
Chromium isotope fractionation during subduction-related metamorphism, black shale weathering, and hydrothermal alteration
}

Xiangli Wang $^{1 *}$, Noah J. Planavsky ${ }^{1}$, Christopher T. Reinhard ${ }^{2}$, Huijuan Zou ${ }^{1}$, Jay J. Ague ${ }^{1}$, Yuanbao $\mathrm{Wu}^{3}$, Benjamin C. Gill ${ }^{4}$, Esther M. Schwarzenbach ${ }^{4}$, Bernhard Peucker-Ehrenbrink ${ }^{5}$

${ }^{1}$ Yale University, Department of Geology and Geophysics, New Haven, Connecticut, USA;

${ }^{2}$ Georgia Institute of Technology, School of Earth and Atmospheric Sciences, Atlanta, Georgia, USA; ${ }^{3}$ China University of Geosciences, Faculty of Earth Sciences, Wuhan, Hubei, China;

$10{ }^{4}$ Virginia Polytechnic Institute and State University, Blacksburg, VA, USA; ${ }^{5}$ Woods Hole

11 Oceanographic Institution, Woods Hole, MA, USA

*Corresponding author: xiangli.wang@yale.edu. 210 Whitney Ave, New Haven CT 06511.

ABSTRACT. Chromium (Cr) isotopes are an emerging proxy for redox processes at Earth's surface. However, many geological reservoirs and isotope fractionation processes are still not well understood. The purpose of this contribution is to move forward our understanding of (1)

Earth's high temperature Cr isotope inventory and (2) Cr isotope fractionations during subduction-related metamorphism, black shale weathering and hydrothermal alteration. The examined basalts and their metamorphosed equivalents yielded $\delta^{53} \mathrm{Cr}$ values falling within a narrow range of $-0.12 \pm 0.13 \%$ ( $2 \mathrm{SD}, \mathrm{n}=30)$, consistent with the previously reported range for the bulk silicate Earth (BSE). Compilations of currently available data for fresh silicate rocks (43

24 samples), metamorphosed silicate rocks (50 samples), and mantle chromites (39 samples) give

$25 \delta^{53} \mathrm{Cr}$ values of $-0.13 \pm 0.13 \%$ o, $-0.11 \pm 0.13 \%$, and $-0.07 \pm 0.13 \%$, respectively. Although the

26 number of high-temperature samples analyzed has tripled, the originally proposed BSE range

27 appears robust. This suggests very limited $\mathrm{Cr}$ isotope fractionation under high temperature

28 conditions. Additionally, in a highly altered metacarbonate transect that is representative of fluid-

29 rich regional metamorphism, we did not find resolvable variations in $\delta^{53} \mathrm{Cr}$, despite significant

30 loss of $\mathrm{Cr}$. This work suggests that primary $\mathrm{Cr}$ isotope signatures may be preserved even in

31 instances of intense metamorphic alteration at relatively high fluid-rock ratios. Oxidative 
32 weathering of black shale at low $\mathrm{pH}$ creates isotopically heavy mobile $\mathrm{Cr}(\mathrm{VI})$. However, a

33 significant proportion of the $\mathrm{Cr}(\mathrm{VI})$ is apparently immobilized near the weathering surface,

34 leading to local enrichment of isotopically heavy $\mathrm{Cr}\left(\delta^{53} \mathrm{Cr}\right.$ values up to $\sim 0.5 \%$ ). The observed

35 large $\mathrm{Cr}$ isotope variation in the black shale weathering profile provides indirect evidence for

36 active manganese oxide formation, which is primarily controlled by microbial activity. Lastly,

37 we found widely variable $\delta^{53} \mathrm{Cr}(-0.2 \%$ to $0.6 \%$ ) values in highly serpentinized peridotites from

38 ocean drilling program drill cores and outcropping ophiolite sequences. The isotopically heavy

39 serpentinites are most easily explained through a multi-stage alteration processes: Cr loss from

40 the host rock under oxidizing conditions, followed by $\mathrm{Cr}$ enrichment under sulfate reducing

41 conditions. In contrast, $\mathrm{Cr}$ isotope variability is limited in mildly altered mafic oceanic crust.

43 Keywords: Chromium isotopes, redox proxies, metamorphism, subduction, hydrothermal 44 alteration, black shale weathering

\section{Introduction}

Chromium (Cr) isotopes (with abundances of $2.36 \%{ }^{54} \mathrm{Cr}, 9.50 \%{ }^{53} \mathrm{Cr}, 83.79 \%{ }^{52} \mathrm{Cr}$, $4.35 \%{ }^{50} \mathrm{Cr}$ ) have wide utility for tracking planetary formation, environmental contamination, and paleoenvironmental evolution. Over the past few decades, studies have utilized $\mathrm{Cr}$ isotope

50 anomalies in different planetary materials to study spatial and/or temporal heterogeneities in the

51 solar system (Birck and Allègre, 1984; Papanastassiou, 1986; Rotaru et al., 1992; Podosek et al.,

52 1997; Shukolyukov and Lugmair, 2006; Trinquier et al., 2007; Qin et al., 2011). In addition,

53 there has been extensive work on using $\mathrm{Cr}$ isotopes to quantify the attenuation of environmental

54 Cr contamination (Ellis et al., 2002; Wanner et al., 2011; Izbicki et al., 2012). More recently,

55 there has been a surge of interest in using $\mathrm{Cr}$ isotopes as a paleoredox proxy (e.g., Frei et al.,

56 2009; Crowe et al., 2013; Planavsky et al., 2014; Reinhard et al., 2014). 
58 Chromium has two major valence states in nature: Reduced, trivalent $\mathrm{Cr}$ (denoted as

$59 \mathrm{Cr}(\mathrm{III})$ hereafter) and oxidized, hexavalent $\mathrm{Cr}$ (denoted as $\mathrm{Cr}$ (VI) hereafter). At circumneutral

$60 \mathrm{pH}, \mathrm{Cr}(\mathrm{III})$ is insoluble and is a trace nutrient, while $\mathrm{Cr}(\mathrm{VI})$ is soluble and carcinogenic (Rai et

61 al., 1989). Therefore, in-situ reduction of $\mathrm{Cr}(\mathrm{VI})$ to $\mathrm{Cr}(\mathrm{III})$ can serve as a means of remediating

$62 \mathrm{Cr}(\mathrm{VI})$ contamination. In Earth's early history, before the emergence of oxygenic photosynthesis,

63 Cr was likely present almost exclusively as $\mathrm{Cr}$ (III) in rocks. After the advent of oxygenic

64 photosynthesis, local and eventually global oxygenated environments passed a critical threshold

65 required for $\mathrm{Cr}(\mathrm{III})$ oxidation to $\mathrm{Cr}(\mathrm{VI})$, in a process likely linked to manganese redox cycling

66 (Eary and Rai, 1987; Fendorf and Zasoski, 1992; Frei et al., 2009). The oxidized Cr(VI) is

67 carried to the oceans as dissolved oxyanion species and eventually deposited in sedimentary

68 rocks, either as $\mathrm{Cr}(\mathrm{VI})$ via adsorption or as $\mathrm{Cr}(\mathrm{III})$, typically via reduction by reductants such as

69 ferrous iron and sulfides (Eary and Rai, 1987; Fendorf and Li, 1996; Pettine et al., 1998; Kim et

70 al., 2001). Use of the $\mathrm{Cr}$ isotope system as a redox proxy is grounded in the notion that there is

71 up to $\sim 6 \%$ o $\mathrm{Cr}$ isotope fractionation during reactions involving electron transfers (Ellis et al.,

72 2002; Schauble et al., 2004; Zink et al., 2010; Wang et al., 2015a), but insignificant Cr isotope

73 fractionations during non-redox-dependent reactions (e.g., Ellis et al., 2004). Studies on modern

74 basaltic weathering profiles have found that isotopically heavy $\mathrm{Cr}$ is oxidatively mobilized into

75 rivers, leaving isotopically light $\mathrm{Cr}$ in the weathered basalt (e.g., Frei and Polat, 2012). Building

76 on this framework, $\mathrm{Cr}$ isotopes have provided a new view of Earth's ocean-atmosphere redox

77 evolution (Frei et al., 2009; Crowe et al., 2013; Planavsky et al., 2014). 
Despite the significant potential of $\mathrm{Cr}$ isotopes as a redox proxy, there are several notable

80 gaps in current knowledge. The purpose of this contribution is to examine a series of currently

81 unresolved or poorly constrained questions that affect the use of the $\mathrm{Cr}$ isotope system as a

82 paleoredox proxy. First, for all $\mathrm{Cr}$ isotope work, it is necessary to establish a robust estimate of

83 the Cr isotope inventory of the solid Earth. Only a few studies have been conducted in the past

84 few years for this purpose. For instance, Schoenberg et al. (2008) and Farkas et al. (2013)

85 proposed bulk silicate Earth (BSE) $\delta^{53} \mathrm{Cr}\left({ }^{53} \mathrm{Cr} /{ }^{52} \mathrm{Cr}\right.$ relative to SRM 979) values of -

$86 \quad 0.124 \pm 0.101 \%$ and $-0.079 \pm 0.129 \%$, respectively. Moynier et al. (2011) reported a bulk Earth

87 (BE) $\delta^{53} \mathrm{Cr}$ value of $-0.32 \pm 0.05 \%$, which is about $0.2 \%$ lighter than the BSE value. The apparent

88 difference between BE and BSE, and its potential implications for planetary differentiation,

89 provides motivation to expand our current knowledge of the high-T Cr isotope inventory. For

90 this purpose, we explored the $\delta^{53} \mathrm{Cr}$ systematics of a range of basalt samples (both alkaline and

91 tholeiitic) from different localities.

92

94 earliest emergence of oxygenic photosynthesis (Frei et al., 2009; Crowe et al., 2013). However,

95 most Archean rocks have been subject to various grades of metamorphism. This provides a

96 strong impetus to investigate the magnitude of $\mathrm{Cr}$ isotope fractionation associated with

97 metamorphic processes. For this reason, we analyzed a set of subduction-related metamorphosed

98 ultramafic rocks and fluid-altered carbonate rocks. The metamorphic age of these rocks range

99 from Neoproterozoic to Phanerozoic. Although the pattern and depth of subduction may differ on

100 the early and recent Earth, the underlying basic physicochemical processes (e.g., deformation,

101 temperature- or concentration-driven diffusion) are not likely to have varied over time. 
102 Furthermore, the Cr isotopic composition of the mantle reservoir has been shown to be the same

103 within error since $\sim 3.5$ billion years ago (Ga) (Farkas et al., 2013). Therefore, $\mathrm{Cr}$ isotope

104 behavior during high temperature metamorphism derived from recent geological time should be 105 applicable to the Archean.

106

Third, our current understanding of the terrestrial Cr cycle is based largely on the study of 108 oxidative weathering of igneous rocks (Middelburg et al., 1988; Van der Weijden and van der 109 Weijden, 1995; Frei et al., 2009; Frei and Polat, 2012; Crowe et al., 2013). However, igneous

110 rocks represent only a small area of the subaerially exposed continental crust relative to

111 sedimentary rocks (e.g., Bluth and Kump, 1991). Therefore, weathering of sedimentary rocks can

112 potentially contribute significantly to riverine $\mathrm{Cr}$ flux to the ocean. Among sedimentary rocks,

113 black shales are of special interest because of their relatively high $\mathrm{Cr}$ concentrations. Given that

114 black shale weathering typically occurs at low $\mathrm{pH}$, the framework developed from basalt

115 weathering (e.g., Crowe et al., 2013; Berger and Frei, 2014; Frei et al., 2014) may not apply.

116 Furthermore, previous studies used lack of Cr isotope fractionation in sedimentary rocks to argue

117 for low atmospheric oxygen levels (e.g., Frei et al., 2009; Frei and Polat, 2012; Crowe et al.,

118 2013; Planavsky et al., 2014). However, absence of Cr isotope fractionation in sedimentary

119 records is not necessarily a robust evidence for absence of oxygen (Planavsky et al., 2014). This

120 is because pyrite oxidation could generate acids and dissolve solid $\mathrm{Cr}$ without $\mathrm{Cr}$ oxidation, and

121 this process leads to $\mathrm{Cr}$ enrichment but no isotope fractionation in sedimentary rocks (Konhauser

122 et al., 2011). To resolve this uncertainty, we targeted a well-studied black shale weathering

123 profile to test whether there is Cr isotope fractionation and $\mathrm{Cr}(\mathrm{III})$ oxidation in a high oxygen but

124 low-pH weathering environment. 
126 Lastly, interaction between seawater and oceanic crust is another process that can affect

127 seawater $\delta^{53} \mathrm{Cr}$ values. Although this process may not be very important on a global scale in the

128 modern oceans (e.g., Reinhard et al., 2013), it may affect local water masses and sediments,

129 given that large $\mathrm{Cr}$ isotope variations have been reported for $\mathrm{Cr}$-rich hydrothermal minerals

130 (Schoenberg et al., 2008; Farkas et al., 2013). Hydrothermal alteration may also have been

131 important for global $\mathrm{Cr}$ isotope mass balance during the early periods of Earth's history due to

132 higher heat flux and more mafic crust. It is essential to determine if there are significant $\mathrm{Cr}$

133 isotope fractionations in hydrothermal systems before using the $\mathrm{Cr}$ isotope composition of

134 marine sediments to track surface oxidative processes. To further our understanding of seawater-

135 oceanic crust interactions, we analyzed the $\mathrm{Cr}$ isotopic compositions of mildly altered oceanic

136 crust and serpentinized peridotite samples from a range of localities.

138 2. Samples

139 We selected samples where geochemistry and geological context have been previously

140 studied. Samples for metacarbonates, weathered black shales, altered oceanic crusts,

141 serpentinites, Wudangshan basalts, and Dabie eclogites used powders from previous studies

142 (references in Table 1). Below we provide only a short overview of the samples/sites and refer to 143 previous work for more in-depth descriptions.

145 2.1. Basalts and eclogites

146 We examined basalt and eclogite samples from the ultra-high pressure Qinling-Tongbai-

147 Dabie Orogenic Belt (QTDOB, Fig. 1). The QTDOB separates the North China Block (NCB) 
and South China Block (SCB), and itself is divided into the South Qinling (SQ) and North

149 Qinling (NQ) orogens by the Shangdan Fault. There were several major episodes of tectonic

150 activity from mid-Proterozoic to Cenozoic time (e.g., Ratschbacher et al., 2003). The tholeiitic

151 and alkaline basalt samples ( 680-755 Ma) were sampled from the SQ, while the eclogite

152 samples ( $\sim 800 \mathrm{Ma})$ were sampled from the NQ. The basalts and eclogites are geographically

153 close to each other and have the same source material (Ling et al., 2002; Wang et al., 2013). We

154 examined the $\mathrm{Cr}$ isotope composition of tholeiitic and alkaline basalts because of their differing

155 oxygen fugacities during formation (e.g., Carmichael and Ghiorso, 1986), which could

156 potentially influence the redox geochemistry of $\mathrm{Cr}$.

We also examined eclogite, metabasalt and metagabbro samples from Corsica, Greece,

159 USA, and Norway—mafic rocks that experienced typical high pressure or ultrahigh-pressure

160 metamorphism. Alpine Corsica (France) consists mainly of ophiolitic rocks and their

161 sedimentary cover that underwent high-pressure blueschist-eclogite facies metamorphism during

162 the Alpine orogeny Malavieille et al., 1998. One Corsican mafic pillow breccia (CRB) is from

163 the Farinole-Volpajola eclogite unit that experienced metamorphism at $\sim 520{ }^{\circ} \mathrm{C}$ and $\sim 2.3 \mathrm{GPa}$

164 (Vital Brovarone et al., 2011).

165

166 Blueschist-eclogite facies can be found in Syros and Tinos islands in Greece. The

167 metamorphism was caused by subduction of the Apulian microplate beneath the Eurasia plate

168 during the Eocene Alpine orogeny (Keiter et al., 2011 and references therein). Peak metamorphic

169 conditions were $\sim 500-550{ }^{\circ} \mathrm{C}$ and $\sim 2.0 \mathrm{GPa}$ (e.g., Trotet et al., 2001; Dragovic et al., 2012).

170 Sample JAGSY-58A $\left(37^{\circ} 26.660^{\prime} \mathrm{N}, 24^{\circ} 53.327^{\prime} \mathrm{E}\right)$ is an Mg-rich metagabbro from Kini Beach, 
171 Syros. It is dominated by large (cm-scale) bright green crystals of Cr-rich omphacite coexisting

172 with phengite and chlorite. Sample JAGTI-1A is an eclogite from the Tinos subduction complex

173 in the Kionia area (Broecker and Enders, 1999).

174

175

The USA Connecticut area experienced eclogite facies metamorphism during the

176 collision of Laurentia with a Taconic arc complex $\sim 456 \mathrm{Ma}$ (Chu et al., in press). Sample

177 JANW-17 is a retrograded eclogite from the Canaan Mountain Formation, northwestern

178 Connecticut, USA (Harwood, 1979a; Harwood, 1979b). The eclogite facies assemblage

179 consisted of omphacite, garnet, hornblende, phengite, epidote, and rutile; "peak" eclogite facies

180 conditions were $\sim 710^{\circ} \mathrm{C}$ and $1.4-1.5 \mathrm{GPa}$ (Chu et al., in press). Sample JAQ-158A is a

181 hornblende cumulate ultramafic rock, consisting mostly of hornblende, orthopyroxene, olivine,

182 phlogopite, aluminous spinel, and pyrrhotite. The hornblende is poikilitic and typically encloses

183 orthopyroxene and olivine. These rocks are found as meter-scale pods and lenses within the

184 ultrahigh-temperature $\left(\sim 1000^{\circ} \mathrm{C}\right)$ gneisses of the Brimfield Schist in northeastern Connecticut,

185 USA, described by Ague and Eckert (2012) and Ague et al. (2013).

The Franciscan Complex of California, USA, formed during eastward-directed

188 subduction beneath the western margin of North America. The samples (CBJB2 and 6001) are

189 from exotic blocks of metamorphosed mafic rock in the Central Belt mélange. Most

190 metamorphic ages in the blocks range from Middle Jurassic to Early Cretaceous (see review in

191 Wakabayashi, 1999). Sample 6001 is from the "Junction School eclogite" metamorphosed at

192 maximum pressures of $1.8-2.2 \mathrm{GPa}$ at $\sim 550{ }^{\circ} \mathrm{C}$ (Page et al., 2007). The other Franciscan sample 
193 (CBJB2) is garnetiferous blueschist from Jenner Beach, which records metamorphic conditions

194 of $\sim 1.3 \mathrm{GPa}$ and $\sim 500{ }^{\circ} \mathrm{C}$ (Krogh et al., 1994).

Sample 4-1 is an ultrahigh-pressure kyanite eclogite from locality 1066 on Fjørtoft island,

197 Norway, metamorphosed at ultrahigh-pressures (UHP) near $4 \mathrm{GPa}$ and temperatures of $\sim 820^{\circ} \mathrm{C}$

198 (Terry et al., 2000). UHP conditions were reached when Baltica was subducted during the

199 Scandian orogeny (e.g., Carswell et al., 2006).

\subsection{Metacarbonates}

202 Greenschist facies metacarbonate samples were taken from the Wepawaug Schist,

203 Connecticut, USA (see Ague, 2003 and references therein). We selected a transect (JAW-197)

204 that starts within a syn-metamorphic vein, through the reaction aureole, and into the wallrock

205 (Fig. 2). Infiltrating fluids precipitated albite, calcite, and quartz in the vein, and replaced

206 muscovite with albite in the reaction aureole. Fluid infiltration occurred under greenschist facies

207 metamorphic conditions $\left(\sim 425^{\circ} \mathrm{C}, 0.6-0.7 \mathrm{GPa}\right)$ during the $\sim 380-410$ Ma Acadian orogeny

208 (Lanzirotti and Hanson, 1996; Ague, 2002; Lancaster et al., 2008). We focused on this transect

209 given that previous studies reported significant mass transfer of various elements including K,

$210 \mathrm{Na}, \mathrm{Rb}, \mathrm{Sr}, \mathrm{Ba}$ and $\mathrm{REE}$, indicating intense alteration at relatively high fluid-rock ratios (Ague, $2112003)$.

212

\section{2.3. Weathered black shale}

214 Weathered black shale samples were obtained from a road cut $\left(37^{\circ} 52.167^{\circ} \mathrm{N}\right.$,

$21583^{\circ} 56.767^{\circ} \mathrm{W}$ ) near Clay City (Powell County, KY, USA) (Fig. 3). The road cut exposes a 
216 weathering profile through the Upper Devonian (365 Myr) Ohio Shale, often referred to as the

217 'New Albany Shale' (NAS). The samples were taken in 2000 (Jaffe et al., 2002) within a single

218 stratigraphic horizon to avoid syndepositional variation. The variations in the vertical position

219 relative to the targeted stratigraphic horizon are estimated to be less than $2 \mathrm{~cm}$. The sample color

220 ranged from brown near the soil surface to black further into the weathering profile. Previous

221 studies have found in the profile loss of organic carbon, pyrite S, mobile elements associated

222 with reduced C/S phases such as Re and Os (Petsch et al., 2000; Petsch et al., 2001b; Jaffe et al.,

223 2002) and disturbance to Re-Os isotope systems (Jaffe et al., 2002; Miller et al., 2015). The pH

224 in the fluids from the shale profile could be as low as 1.8-2.1 (Sullivan et al., 1988; Jaffe et al.,

225 2002). The outcrop is located south of the range of the late Cenozoic North American glaciation;

226 therefore, weathering likely began before the onset of ice sheet growth. However, there are no

227 robust estimates of the timescale of soil development.

228

229

2.4. Altered oceanic crust and serpentinites

230 We examined mildly hydrothermally altered oceanic crust samples derived from Ocean

231 Drilling Program (ODP) Hole 504B (Fig. 4) spanning the upper ocean crust in the equatorial East

232 Pacific (e.g., Alt et al., 1986; Bach et al., 2003). This is so far the deepest drill core into the

233 oceanic crust and it has generated invaluable information on the petrology, geochemistry and

234 physics of the upper oceanic crust over the past 20 years (Bach et al., 2003 and references

235 therein). The basement section of the core (i.e., below 274.5 meter of sediments) can be divided

236 into three zones (from top to bottom): a 571.5 meter Volcanic Zone (VZ) primarily consisting of

237 pillowed and massive basalt flows; a 209 meter thick Transition Zone (TZ) with abundant dikes

238 mixed with pillows and flows; and finally a $>1045$ meter Sheeted Dike Complex (SDC). There is 
239 a high percentage of brecciation in the TZ, and limited brecciation in other zones $(\sim 5 \%)$.

240 Alteration is non-pervasive and is primarily concentrated in brecciated localities within the TZ.

241 Samples included pillows (P), massive flows (M), breccias (B), and dikes (D). Samples with

242 similar characteristics in each section were mixed in representative proportions in order to make

243 composite samples (see Bach et al., 2003). Oxidative alteration is restricted to the uppermost

$244200-300 \mathrm{~m}$ of basement where the permeability is high, with zoned oxidation halos commonly

245 developed along clay/carbonate/oxyhydroxide grains (e.g., Alt et al., 1996). The alteration in the

246 lower part of the VZ becomes non-oxidative and with temperatures $<150^{\circ} \mathrm{C}$. Alteration

247 temperature steeply increases to $>250^{\circ} \mathrm{C}$ within the upper $\mathrm{TZ}$ and then up to $500-600^{\circ} \mathrm{C}$ in the 248 SDC.

251 Atlantic Ridge (MAR) $15^{\circ} 20^{\prime} \mathrm{N}$ fracture zone, an ophiolite sequence in the Northern Apennines

252 in Italy, and a mélange from the Syros subduction complex. We investigated three drill cores

253 from the Iberian margin: Holes 897C and 897D from ODP Leg149 (see Sawyer et al., 1994), and

254 Hole 1070A from ODP Leg 173 (see Whitmarsh et al., 1998) (Fig. 5B). The peridotites from Site

255897 are nearly $100 \%$ serpentinized with only minor olivine and pyroxene preserved.

256 Serpentinization occurred at low temperatures $<150^{\circ} \mathrm{C}$ near the seafloor with high water/rock

257 ratios and relatively high $f \mathrm{O}_{2}$ coinciding with complete serpentinization and depletion of ferrous

258 iron (Alt and Shanks, 1998). Olivine and orthopyroxene are replaced by mesh- and bastite-

259 textured serpentine and minor magnetite. Two samples (897C-3 and 897C-7) were obtained from

260 the 680-710 meter section of Hole 897C and another two samples (897D-9 and 897D-13) were

261 obtained from the 742-773 meter section of Hole 897D (Fig. 5D). Three samples (1070A-1, 

1070A-2, 1070A-3) were obtained from the 705-707 meter section of Hole 1070A (Fig. 5E). In

263 the sampled sections of Hole $1070 \mathrm{~A}$, between $95 \%$ and $100 \%$ of the primary minerals are

264 replaced by serpentine, but with increasing depth primary orthopyroxene and olivine can be 265 sporadically found (Whitmarsh et al., 1998). Sampled sections from Legs 149 and 173 have 266 elevated sulfur concentrations and negative $\delta^{34} \mathrm{~S}$ values that suggest extensive microbial

267 reduction of seawater-sourced sulfate (Alt and Shanks, 1998; Schwarzenbach et al., 2012). Late 268 low-temperature fluid circulated through the upper part of the serpentinite and resulted in the 269 formation of abundant carbonate veins (Schwarzenbach et al., 2013).

$2721268 \mathrm{~A}$ and 1272A (Fig. 5A). Two samples were obtained from each core: 1268A-1 and 1268A-2 273 in the 35-85 meter section, and 1272A-5 and 1272A-6 from the 99-108 meter section (Fig. 5C).

274 The sampled interval of Hole 1272A comprises serpentinized harzburgite with minor dunite. The 275 presence of iowaite in this section suggests fairly oxidizing conditions (Bach et al., 2004). The 276 sampled interval of Hole 1268A comprises serpentinized and talc-altered harzburgite and dunite 277 with pyrite veins (Paulick et al., 2006). At the same time, peridotites underwent two-stage 278 alteration: initial serpentinization forming serpentine + magnetite \pm pyrite, followed by talc 279 replacing serpentine (Alt et al., 2007). The serpentinization temperatures are estimated to be $280<150^{\circ} \mathrm{C}$ and $250-350^{\circ} \mathrm{C}$ for $1270 \mathrm{~A}$ and $1268 \mathrm{~A}$, respectively. 
285 details in Schwarzenbach et al., 2013). Extensive calcite veins imply high water-rock ratios and

286 oxidizing conditions with carbonate precipitation at $<50-150^{\circ} \mathrm{C}$ and serpentinization

287 temperatures $<240^{\circ} \mathrm{C}$ (Schwarzenbach et al., 2013).

290 Syros were also analyzed (JAGSY-8A-2, -12A, and -13C). Sample 8A-2 is rich in talc and

291 chlorite and is likely a physico-chemical admixture of ultramafic mélange matrix and

292 metasomatised metamafic mélange block material (e.g., Marschall and Schumacher, 2012).

293 Samples -12C and -13C are mantle-derived serpentinites from the mélange.

\section{3. Methods}

Samples provided as rock chips were crushed using a ceramic jaw crusher and then

297 powdered with an agate mill. Powders (30 to $100 \mathrm{mg}$ ) were then digested with mixed $\mathrm{HNO}_{3}$ and 298 HF (3:1) on a hotplate. Fluorides were dissolved by repeated fluxing with $6 \mathrm{~N} \mathrm{HCl}$. Element 299 concentrations were measured on a Thermo Scientific ElementXR ICP-MS. Prior to Cr

300 purification via ion exchange methods, sample aliquots containing $\sim 1 \mu \mathrm{g}$ Cr were spiked with a

$301{ }^{50} \mathrm{Cr}-{ }^{54} \mathrm{Cr}$ double spike $\left({ }^{50} \mathrm{Cr} /{ }^{52} \mathrm{Cr}=462.917,{ }^{53} \mathrm{Cr} /{ }^{52} \mathrm{Cr}=0.580,{ }^{54} \mathrm{Cr} /{ }^{52} \mathrm{Cr}=354.450\right.$, calibrated in the 302 Department of Geology, University of Illinois at Urbana-Champaign) so that the spike/sample 303 ratio (i.e., $\left.\left({ }^{54} \mathrm{Cr}\right)_{\mathrm{spk}} /\left({ }^{52} \mathrm{Cr}\right)_{\mathrm{smp}}\right)$ was about 0.5 .

For carbonate samples, we purified $\mathrm{Cr}$ following the methods described in Bonnand et al.

306 (2011). This method utilizes the cation exchange resin AG50W-X8 (200-400 mesh) to separate $307 \mathrm{Cr}$ (III) cations from other matrix elements. For silicate samples we adopted procedures from 
Schoenberg et al. (2008), which utilize an anion exchange resin AG1-X8 (100-200 mesh) to

309 separate $\mathrm{Cr}(\mathrm{VI})$ anions from matrix elements. For samples high in $\mathrm{Fe}, \mathrm{Ti}$, and $\mathrm{V}$, further

310 procedures are needed to remove these elements because they cause isobaric interferences.

311 Residual Fe was separated from $\mathrm{Cr}$ in $6 \mathrm{~N} \mathrm{HCl}$ by passing it through a micro column filled with

$3120.3 \mathrm{~mL}$ AG1-X8 (100-200 mesh) anion exchange resin; sample Cr was collected immediately

313 after loading onto the column. Residual $\mathrm{Ti}$ and $\mathrm{V}$ were cleaned with a micro column filled with

$3140.3 \mathrm{~mL}$ AG 50W-X8 (200-400 mesh) cation resin following previous methods (Trinquier et al.,

315 2008). The yield for the Schoenberg et al. (2008) method combined with Fe and Ti removal

316 procedures was typically higher than $80 \%$. The yield for the Bonnand et al. (2011) method

317 combined with $\mathrm{Fe}$ and Ti removal procedures were typically $\sim 70 \%$. These yields are acceptable

318 since the ${ }^{50} \mathrm{Cr}-{ }^{54} \mathrm{Cr}$ double spike was added before column procedures and therefore, any isotope

319 fractionation due to incomplete recovery is corrected. Procedural blanks were $\sim 0.7 \mathrm{ng}$ and $\sim 20$

320 ng for the cation exchange and anion exchange methods, respectively. The relatively high blank

321 for the anion exchange method was due to the use of the oxidant ammonium persulfate [Acros

$322(99+\%)$ and Sigma Aldrich ( $\geq 98 \%)$ ]. Sample to blank signal ratios range from 1400:1 to 50:1

323 and blank $\delta^{53} \mathrm{Cr}$ was measured to be $0.0 \pm 0.2 \%$. Therefore, blank correction was not performed.

Chromium isotopic compositions were measured on a Neptune Plus MC-ICP-MS housed in the Yale Metal Geochemistry Center in the Department of Geology \& Geophysics. Purified Cr

327 samples dissolved in $0.7 \mathrm{~N} \mathrm{HNO}_{3}$ with concentrations of $\sim 250 \mu \mathrm{g} / \mathrm{g}$ were introduced to the

328 plasma with a PFA $\mu$ Flow nebulizer $(\sim 50 \mu \mathrm{L} / \mathrm{min})$ coupled with an Apex IR desolvating

329 introduction system (Elemental Scientific) without additional gas or membrane desolvation. With

330 a standard sample cone and X skimmer cone and under high-resolution mode, the obtained 
331 sensitivity was $\sim 3 \times 10^{-10} \mathrm{~A}^{52} \mathrm{Cr}$ on $1 \mu \mathrm{g} / \mathrm{g}$ Cr solution. All ion beams were measured on faraday

332 detectors. The isotopes ${ }^{49} \mathrm{Ti},{ }^{51} \mathrm{~V}$, and ${ }^{56} \mathrm{Fe}$ were measured to monitor and correct for isobaric

333 interferences of ${ }^{50} \mathrm{Ti},{ }^{50} \mathrm{~V}$, and ${ }^{54} \mathrm{Fe}$. The unprocessed NIST SRM 979 standard was analyzed after

334 every three samples to monitor instrument drift, which was $<0.1 \%$ (Fig. 6). Sample $\delta^{53} \mathrm{Cr}$ values

335 were normalized to the average value of the bracketing NIST SRM 979. The NIST SRM 3112a

336 and geostandard BHVO-2 (USGS) were also treated as samples through the digestion and ion

337 exchange procedures and yielded $\delta^{53} \mathrm{Cr}$ values of $-0.01 \pm 0.08 \%$ o $(2 \mathrm{SD}, \mathrm{n}=10)$ and $-0.11 \pm 0.08 \%$ o

338 (2SD, $\mathrm{n}=7$ ), respectively (Table S1), after normalization to NIST SRM 979. These values agree

339 well with previously reported values (Schoenberg et al., 2008). Therefore, we used 0.08\%o as the

340 external reproducibility for samples.

\section{4. Results}

343 Results for all samples are provided in Table 1 and below we describe each sample 344 groups separately.

\subsection{Basalts and eclogites}

347 Over a wide range of Cr concentrations (Fig 7.), the examined basalts and eclogites 348 yielded $\delta^{53} \mathrm{Cr}$ values within a narrow range, $-0.12 \pm 0.13 \%$ ( $\left.2 \mathrm{SD}, \mathrm{n}=33\right)$. There was no

349 analytically resolvable difference in $\delta^{53} \mathrm{Cr}$ values between alkaline basalt, tholeiitic basalt, 350 metabasalt, metagabbro, and eclogite samples. 
Values for $\mathrm{Cr} / \mathrm{Zr}$ ( $\mathrm{Zr}$ serving as a relatively immobile element for normalization

354 purposes) showed a decreasing trend from the relatively fresh wallrock to the vein-wallrock

355 boundary. This matches well with the trend observed in $\mathrm{K} / \mathrm{Zr}$ (Fig. 8), suggesting loss of

356 elements during fluid-rock interaction. The $\mathrm{Cr} / \mathrm{Zr}$ ratios in the unaltered portion of the traverse

357 lie slightly above the value estimated for the upper continental crust (Rudnick and Gao, 2003),

358 but decrease to below this value approaching the vein. The metacarbonate rocks were pulverized

359 in agate only, without contact with ceramic material. Therefore, the use of $\mathrm{Zr}$ as the

360 normalization element is valid. Despite the significant mobility of Cr evidently caused by the

361 vein-forming fluid, the $\delta^{53} \mathrm{Cr}$ values along the transect are all within analytical of one another.

363 4.3. Black shale weathering

364 We observed enrichment of $\mathrm{Cr}$ and high $\delta^{53} \mathrm{Cr}$ values in the most altered portions of the

365 NAS black shale weathering profile (Fig. 9). The Cr/Ti ratios throughout the weathering profile

366 range from 0.015 to 0.021 , which overlap with the ranges reported for the upper continental crust

367 (0.0158 to 0.0240, Condie, 1993; McLennan, 2001; Rudnick and Gao, 2003). However, the

$368 \mathrm{Cr} / \mathrm{Ti}$ ratios in the most weathered section are about $30 \%$ higher than the pristine shale and the

$369 \delta^{53} \mathrm{Cr}$ value is $0.5 \%$ heavier. The enrichment of $\mathrm{Cr}$ in the surface sample is in sharp contrast to

370 depletion of organic matter and the mobile element rhenium. Deeper samples in the profile have

$371 \delta^{53} \mathrm{Cr}$ values that are similar to or slightly higher than that in the pristine shale, except for one

372 sample (NAS-20), which yielded a $\delta^{53} \mathrm{Cr}$ value of $-0.5 \%$. 
376 between $-0.22 \%$ and $-0.17 \%$, with an average of $-0.18 \pm 0.10 \%$ ( $2 \mathrm{SD}, \mathrm{n}=7)$, which is within the

377 previously reported range for bulk silicate earth (BSE) (Schoenberg et al., 2008; Moynier et al.,

378 2011; Farkas et al., 2013) and identical to the measured basalts reported above. Chromium

379 concentrations range from $199 \mu \mathrm{g} / \mathrm{g}$ to $387 \mu \mathrm{g} / \mathrm{g}$. No systematic trends were observed in $\delta^{53} \mathrm{Cr}$

380 values between different alteration zones. However, $\mathrm{Cr}$ concentrations tend to be lower in the

381 brecciated zone, where alteration is most intensive.

382

In contrast, the examined serpentinite samples had a range of $\delta^{53} \mathrm{Cr}$ values of $-0.18 \%$ to

$3840.52 \%$ and concentrations varied from $595 \mu \mathrm{g} / \mathrm{g}$ to $3038 \mu \mathrm{g} / \mathrm{g}$ (Fig. 12). Samples with lower $\mathrm{Cr}$

385 concentrations tend to have larger $\delta^{53} \mathrm{Cr}$ values. Further, $\mathrm{Cr}$ concentrations in most of the altered

386 peridotites are markedly lower than the estimated average mantle value of $2625 \mu \mathrm{g} / \mathrm{g}$ (blue line

387 in Fig. 12; Sun and McDonough, 1989), indicating loss of Cr during serpentinization.

\section{5. Discussion}

390 5.1. Basalts and eclogites

391 The $\delta^{53} \mathrm{Cr}$ values of the investigated basalt and eclogite samples fall within previously

392 reported ranges of the BSE (Schoenberg et al., 2008; Farkas et al., 2013; Shen et al., 2015) (Fig.

393 7). Based on high temperature rocks/minerals published so far (Schoenberg et al., 2008; Farkas

394 et al., 2013; Shen et al., 2015; this study), the average $\delta^{53} \mathrm{Cr}$ values for fresh silicate rocks (43

395 samples), metamorphosed silicate rocks (50 samples), and mantle chromites (39 samples) are -

$3960.13 \pm 0.13 \%$, $-0.11 \pm 0.13 \%$, and $-0.07 \pm 0.13 \%$, respectively (Table S2). All three groups are 
within error the same, suggesting that there is very limited $\mathrm{Cr}$ isotope fractionation under high

398

399

400

401

402

403

404

405

406

407

408

409

410

411 fractionation is not likely under high temperatures, as predicted by ab initio calculations

412 (Moynier et al., 2011) and natural observation of a wide range of high-temperature rocks

413 (Schoenberg et al., 2008; Farkas et al., 2013; Shen et al., 2015; this study). Therefore, the

414 apparent difference in $\delta^{53} \mathrm{Cr}$ values between the $\mathrm{BSE}$ and $\mathrm{BE}$, if true, suggests that either core-

415 mantle differentiation on Earth occurred under relatively low temperature conditions (e.g., during

416 early accretion, Moynier et al., 2011) or that some kinetic process (e.g., thermal diffusion, Furry

417 et al., 1939; Richter et al., 2008; Huang et al., 2010) may have induced Cr isotope fractionation

418 under conditions of higher temperature and pressure. Further analysis of a range of solar system

419 materials can be leveraged to test these alternate hypotheses. 


\section{5.2. Metacarbonates}

422 Despite significant element mobility during alteration of the Wepawaug Schist sample,

423 there appears to be no significant effect on the $\mathrm{Cr}$ isotope composition (Fig. 8). As muscovite

424 was almost certainly the major Cr host in the metacarbonate rock, the metasomatic destruction of

425 this phase led to the observed losses of $\mathrm{Cr}$ and $\mathrm{K}$ (Ague, 2003). The $\delta^{53} \mathrm{Cr}$ values near and within

426 the reaction aureole are slightly lower than the more distal samples by $\sim 0.04 \%$, and the trend

427 appears to be systematic, but the variation is well within the analytical uncertainty. This lack of

428 significant variation in $\delta^{53} \mathrm{Cr}$ values suggests that rocks that have experienced significant

429 metamorphic alteration at relatively high fluid-rock ratios may still record primary $\mathrm{Cr}$ isotope

430 signatures, as long as there is no enrichment of $\mathrm{Cr}$ from isotopically distinct sources. However,

431 the presence of organic matter and pyrite (Fig. 2) in the Wepawaug Schist carbonate rock

432 indicates overall low $\mathrm{fO}_{2}$. Oxidizing metamorphic conditions should be tested in the future for

433 potentially pronounced $\mathrm{Cr}$ isotope effects.

$435 \quad$ 5.3. Black shale weathering

436 There is significant enrichment of $\mathrm{Cr}$ and large variation (up to 1\%o) in $\mathrm{Cr}$ isotopic

437 composition in the New Albany Shale weathering profile (Fig. 9). The positive $\delta^{53} \mathrm{Cr}$ values in 438 all but one sample (NAS20) and the enrichment of $\mathrm{Cr}$ at the profile surface is in sharp contrast to 439 those observed in basaltic weathering profiles (Frei and Polat, 2012; Crowe et al., 2013; Frei et 440 al., 2014), where Cr depletion and negative isotope fractionation were observed. We propose that 441 the Cr enrichment on the surface of the shale profile is due to short transport followed by

442 immobilization of isotopically heavy $\mathrm{Cr}(\mathrm{VI})$. The immobilization could be caused by quantitative 
443 reduction or adsorption. Reduction is possible given the elevated remaining organic carbon 444 content $(\sim 2$ wt.\%) despite significant loss relative to the less weathered interior portion of the 445 outcrop (6-8\%). However, the remaining organic is unlikely to be labile and active enough to 446 reduce Cr(VI) (e.g., Petsch et al., 2001b). Alternatively, given the high Fe oxide concentrations

447 (likely formed during initial organic carbon loss) near the surface (Fig. 9E), adsorption of Cr(VI)

448 to Fe oxides or trapping of $\mathrm{Cr}(\mathrm{VI})$ during oxide precipitation (co-precipitation) may also have 449 lead to the enrichment of $\mathrm{Cr}$ on the surface. Indeed, there is a positive correlation between $\mathrm{Cr} / \mathrm{Ti}$ 450 ratios and $\mathrm{Fe}$ concentrations (Fig. 10). We emphasize that the observed behavior of Cr isotopes 451 in this profile differs from that of Re isotopes in that mobile heavy Re is not immobilized near 452 the soil surface, but instead lost from the profile (Miller et al., 2015).

The single sample with a negative $\delta^{53} \mathrm{Cr}(-0.52 \%)$ also has two possible explanations.

455 First, this sample is found close to the redox front within the weathering transect (e.g., Jaffe et 456 al., 2002), and it is possible that this sample locality was undergoing active redox reaction and 457 influenced by local partial $\mathrm{Cr}$ reduction during weathering that is not yet apparent in, for 458 example, organic carbon content. Therefore, this sample may simply have captured the partially 459 reduced, isotopically light $\mathrm{Cr}$ (III). The Re content in the same sample is enriched relative to 460 adjacent samples, which is consistent with reductive sequestration of redox-sensitive elements at 461 this particular locality. However, by mass balance, significant $\mathrm{Cr}$ enrichment would have been 462 required to result in such a negative $\delta^{53} \mathrm{Cr}$ value, and such enrichment is not observed for this 463 sample and is thus unlikely. Alternatively, the negative $\delta^{53} \mathrm{Cr}$ value may be due to loss of heavy 464 Cr during isotope exchange between solid $\mathrm{Cr}(\mathrm{III})$ and soluble $\mathrm{Cr}(\mathrm{VI})$ carried by weathering 
465 fluids (e.g., Wang et al., 2015a). This isotope exchange process is able to generate large isotope 466 fractionation without net changes in $\mathrm{Cr}$ enrichment. profile provides clear evidence that there can be active $\mathrm{Cr}$ redox cycling in low $\mathrm{pH}$ oxidative

470 weathering environments. Manganese oxides are so far the only oxidants found to induce 471 significant $\mathrm{Cr}$ (III) oxidation in natural environments (e.g. Eary and Rai, 1987). Formation of

472 manganese oxides is primarily mediated by microorganisms (Tebo et al., 2004) whose growth

473 has been generally deemed to be hindered under low pH conditions (e.g., Mayanna et al., 2015)

474 such as those found in black shale weathering environments (Sullivan et al., 1988; Jaffe et al., 475 2002). However, some studies have reported microorganisms that can thrive under acidic 476 conditions (Petsch et al., 2001a) and generate manganese oxides (Mayanna et al., 2015). This is

477 in line with our observation of relatively large $\mathrm{Cr}$ isotope fractionations in an acidic shale 478 weathering environment.

The examined profile is only a single system, but it provides support for the notion that a 481 lack of $\mathrm{Cr}$ isotope variation in sedimentary records (e.g., as captured in pre-Great Oxidation 482 Event and mid-Proterozoic sedimentary rocks) cannot be well explained by oxidative weathering 483 of a poorly buffered shale-dominated catchment. Instead, it is more likely linked to low oxygen 484 levels at Earth's surface (e.g., Frei et al., 2009; Planavsky et al., 2014). However, this inference 485 rests on the assumption that weathering of black shales is a significant source of $\mathrm{Cr}$ to rivers and 486 thus oceans. Given the $\mathrm{Cr}$ enrichment in the outer portions of the weathering profile, an 487 intriguing alternative possibility is that weathering of organic-rich shale may not contribute 
488 significant $\mathrm{Cr}$ fluxes into rivers, and may instead serve as a 'trap' of $\mathrm{Cr}$ that is ${ }^{53} \mathrm{Cr}$-enriched. In 489 this scenario, our finding of significant $\mathrm{Cr}$ isotope fractionation during black shale weathering 490 may not be relevant to Precambrian cycling of mobile, unfractionated Cr. More studies of the

491 behavior of redox-sensitive isotope systems (e.g. Cr, Mo, Re, U) in organic-rich shale weathering 492 profiles coupled to surface water analyses should be conducted in the future in order to better 493 constrain contributions to global mass balance from weathering sedimentary rocks relative to 494 weathering of igneous rocks.

\subsection{Hydrothermal alteration}

497 The majority of the analyzed serpentinites (Fig. 12) show elevated $\delta^{53} \mathrm{Cr}$ values (up to $498 \sim 0.5 \%$ ) compared to fresh peridotite $(-0.10 \%$ to $-0.21 \%$; Schoenberg et al., 2008$)$. The values 499 fall within previously reported values for serpentinites (-0.17\% to 1.2\%o, Farkas et al., 2013).

500 Two processes may be responsible for producing the positive $\delta^{53} \mathrm{Cr}$ values: (1) incorporation of 501 isotopically heavy $\mathrm{Cr}$ from seawater; and (2) loss of isotopically light $\mathrm{Cr}$ from peridotite during 502 hydration processes.

A simple two-end-member mass balance calculation indicates that direct addition of 505 seawater $\mathrm{Cr}$ to fresh peridotite is not likely to induce such large isotope shifts. We assume that: 506 (1) Seawater (0.2 ng/g Cr, Jeandel and Minster, 1987) circulates through the upper oceanic crust 507 (2625 $\mu \mathrm{g} / \mathrm{g} \mathrm{Cr}$, Sun and McDonough, 1989; $1000 \mathrm{~m}$ thick with a density of $2700 \mathrm{~kg} / \mathrm{m}^{3}$, 508 Staudigel, 2014; area of $2.97 \times 10^{8} \mathrm{~km}^{2}$, Parsons, 1981) with a water flux of about $6.4 \times 10^{14} \mathrm{~kg} / \mathrm{yr}$ 509 (Staudigel, 2014) for 100 million years; (2) Cr from seawater gets evenly added to the upper 510 oceanic crust; and (3) $\mathrm{Cr}$ in seawater is completely sequestered. Given these assumptions, which 
511 are conservative with respect to both water flux and sealing time for the oceanic crust, we find

512 that the amount of $\mathrm{Cr}$ supplied by seawater within the 100 million-year alteration timeframe is

513 about six orders of magnitude lower than the size of the native Cr reservoir of the upper oceanic

514 crust. Thus, the isotope effect on the upper oceanic crust as a whole should be negligible.

515 However, we acknowledge that this simple calculation does not rule out localized $\mathrm{Cr}$

516 enrichments. Nevertheless, it is much more likely that isotope variations in serpentinites

517 originate from redox cycling within the upper oceanic crust, rather than addition of $\mathrm{Cr}$ directly

518 from seawater.

Loss of isotopically light $\mathrm{Cr}$ during the hydration processes is a possible explanation for

521 the enrichment of heavy Cr during serpentinization. However, previous experimental (Zink et al., 522 2010) and field (Frei and Polat, 2012; Crowe et al., 2013) observations found that heavy isotopes

523 are preferentially lost during $\mathrm{Cr}$ oxidation. Importantly, measurements on crocoite $\left(\mathrm{PbCrO}_{4}\right)$,

524 which is thought to precipitate directly from oxic hydrothermal fluids, yielded heavy $\delta^{53} \mathrm{Cr}$

525 values ranging from $0.01 \%$ to $1.96 \%$ (Schoenberg et al., 2008; Farkas et al., 2013). This

526 direction of isotope fractionation during oxidation of $\mathrm{Cr}(\mathrm{III})$ is opposite to the prediction by

527 mass-dependent kinetic isotope effect, whereby light isotopes tend to react 'faster' and thus

528 enrich in the product (e.g. Bigeleisen, 1965), but is consistent with the prediction by equilibrium

529 isotope effect, whereby heavier isotopes preferentially enrich in species with stronger chemical

530 bonds, i.e. $\mathrm{CrO}_{4}{ }^{2-}$ (Schauble et al., 2004; Wang et al., 2015a). However, the fractionation during

531 oxidation is still poorly constrained, and likely depends on the oxidation kinetics. Further, there

532 is some evidence of isotopically light $\mathrm{Cr}(\mathrm{VI})$ generated by oxidation (Bain and Bullen, 2005),

533 possibly due to a kinetic isotope effect. Therefore, we can estimate the size of the oxidation 
534 fractionation assuming all $\mathrm{Cr}$ loss from peridotite to fluids is due to oxidation. We get a

535 fractionation factor ( $\varepsilon_{\text {fluid-peridotite }}$ ) of $-0.6 \%$ to $-0.17 \%$ (Fig. 12$)$, using a Rayleigh fractionation 536 model:

$538 \delta^{53} \mathrm{Cr}=\left[\delta^{53} \mathrm{Cr}_{\text {initial }}+10^{3}\right] f^{(\alpha-1)}-10^{3}$,

540 where $\delta^{53} \mathrm{Cr}_{\text {initial }}$ is the $\delta^{53} \mathrm{Cr}$ value of peridotites and a value of $-0.2 \%$ is used (the lowest of the

541 examined serpentinites); $f$ is the fraction of $\mathrm{Cr}$ remaining after serpentinization, calculated as

$542[\mathrm{Cr}]_{\text {serpentinite }}$ divided by the mantle value $(2625 \mu \mathrm{g} / \mathrm{g} \mathrm{Cr}) ; \alpha$ is the fractionation factor and can be

543 converted to $\varepsilon_{\text {fluid-peridotite }}$ by the equation:

$1000(\alpha-1) \approx \varepsilon_{\text {fluid-peridotite }}$

An alternative mechanism for generating isotopically heavy serpentinite is through multi548 stage alteration. The $\mathrm{Cr}$ concentrations in the examined serpentinites are up to about four times

549 lower than the average mantle value $(2625 \mu \mathrm{g} / \mathrm{g}$, Sun and McDonough, 1989). This suggests that

550 the peridotites experienced net $\mathrm{Cr}$ loss. The loss of $\mathrm{Cr}$ is likely through oxidative mobilization of $551 \mathrm{Cr}(\mathrm{III})$ in peridotite instead of direct dissolution, given the extremely low solubility of $\mathrm{Cr}$ (III) 552 (Rai et al., 1987) under the high pH (9-9.8) conditions generated by serpentinization (Kelley et 553 al., 2001; Kelley et al., 2005). However, serpentinization generally proceeds under reducing 554 conditions in the early stages (e.g., Berndt et al., 1996; Seyfried et al., 2007), usually at high 555 temperatures, followed by oxidizing conditions during later stages (e.g., Alt and Shanks, 1998), 556 usually at low temperatures. Therefore, the loss of Cr likely occurred during later stages of 
557 serpentinization. The $\mathrm{Cr}$ isotope fractionation during oxidation of solid-state $\mathrm{Cr}(\mathrm{III})$ is not been

558 well understood, but we expect it to be small due to a "rind effect" that has been reported for

559 oxidation of solid-phase U(IV) by dissolved oxygen (see Wang et al., 2015b). Further, the long

560 timescales of hydrothermal circulation $\left(\sim 10^{6}\right.$ years $)$ may allow isotope equilibration between

$561 \mathrm{Cr}(\mathrm{III})$-bearing residual peridotite and $\mathrm{Cr}(\mathrm{VI})$-bearing serpentinization fluid. However, such

562 isotope equilibration should lead to isotopically light $\mathrm{Cr}$ (III) phase (Schauble, 2007; Wang et al.,

563 2015a), unless the amount of $\mathrm{Cr}(\mathrm{VI})$ in the fluid dominates the $\mathrm{Cr}$ contained in the serpentinized

564 peridotites and is very enriched in ${ }^{53} \mathrm{Cr}\left(\delta^{53} \mathrm{Cr}>5.8 \%\right)$. Therefore, it is possible that the high

$565 \delta^{53} \mathrm{Cr}$ values in the serpentinized peridotites could alternatively be caused by addition of

566 isotopically heavy $\mathrm{Cr}$ from alteration fluids after the peridotite had lost the majority of their

567 original Cr. Fluids carrying the oxidized $\mathrm{Cr}(\mathrm{VI})$ may experience partial reduction during

568 migration, leading to isotopically heavy residual $\mathrm{Cr}(\mathrm{VI})$ in the fluid. This isotopically heavy

$569 \mathrm{Cr}(\mathrm{VI})$ can be added to the $\mathrm{Cr}$-depleted serpentinites via reduction. By mass balance, $\delta^{53} \mathrm{Cr}$

570 values of serpentinites that have lost the majority of their $\mathrm{Cr}$ can be relatively easily altered by

571 addition of isotopically heavy $\mathrm{Cr}$ from fluids.

572

573 Such a multi-stage redox alteration model as outlined above is consistent with sulfur

574 isotope data from the serpentinite samples obtained from Legs 149 and 173 (Alt and Shanks,

575 1998; Schwarzenbach et al., 2012). Both sulfide and sulfate concentrations (Fig. 13D) in these

576 samples are much higher than the average total S in the mantle (McDonough and Sun, 1995).

577 Furthermore, the $\delta^{34} \mathrm{~S}$ values for both sulfide and sulfate in the serpentinites (Fig. 13C) are lower

578 than the seawater and mantle value (see Alt and Shanks, 1998). These observations suggest

579 significant addition of isotopically light sulfur (Fig. 13C) through sulfate reduction. Such 
580 reducing conditions may have enabled quantitative reduction of isotopically heavy $\mathrm{Cr}(\mathrm{VI})$

581 carried by the fluids. Furthermore, transport of sulfate supports that oxic conditions existed in the

582 system to allow loss of $\mathrm{Cr}$ from peridotites. However, to satisfy isotope mass balance there must

583 be isotopically light $\mathrm{Cr}$ produced by partial reduction when the fluid migrates within the upper

584 oceanic crust. As the fluid migrates, the partially reduced, isotopically light $\mathrm{Cr}$ may have been

585 diluted into less altered samples with roughly $\mathrm{BSE} \delta^{53} \mathrm{Cr}$ values with high $\mathrm{Cr}$ concentration, and

586 thus making the isotope shift muted. Alternatively, our sampling may have missed a zone of the

587 serpentinizing system with light $\delta^{53} \mathrm{Cr}$ values.

In any case, large isotope fractionations in serpentinizing systems are significant given

590 that small $\mathrm{Cr}$ isotope variations in sedimentary rocks proximal to hydrothermal systems have

591 been used to track the emergence of biological oxygen production. This and other recent work

592 (Farkas et al., 2013) indicates that a hydrothermal origin of $\mathrm{Cr}$ must be ruled out before

593 fractionated $\mathrm{Cr}$ in the sedimentary record can be linked unambiguously with terrestrial $\mathrm{Cr}$ redox

594 cycling. Although we expect that from a mass balance perspective the overall effect of

595 serpentinizing systems on the Earth surficial Cr isotope cycle is likely to be small on a global

596 scale, the possibility for strongly fractionated high-temperature $\mathrm{Cr}$ sources in restricted basins or 597 regions should be kept in mind in future studies (e.g., Farkas et al., 2013).

599 6. Concluding marks

$600 \quad$ Basalts and their metamorphic products yielded similar $\delta^{53} \mathrm{Cr}$ values to published values

601 of silicates and chromites. This suggests limited $\mathrm{Cr}$ isotope fractionation under high temperature

602 conditions. Furthermore, carbonate rocks that have experienced significant fluid infiltration 
during regional metamorphism show very limited $\mathrm{Cr}$ isotope fractionation. These results suggest

604 that sedimentary and igneous Cr isotope signatures may not to be strongly altered by

605 metamorphic alteration, as long as there is minimal transport of isotopically distinct $\mathrm{Cr}$ to/from

606 the system and there is no significant shift in redox state. active redox cycling of $\mathrm{Cr}$ driven by manganese oxide formation in an acidic black shale weathering environment. However, net isotope variation may be restricted for the shale weathering profile as a whole due to efficient short-range immobilization of the oxidized $\mathrm{Cr}(\mathrm{VI})$. isotopes significantly. However, serpentinization of ultramafic peridotites results in serpentinites

615 with large positive $\delta^{53} \mathrm{Cr}$ values. These high $\delta^{53} \mathrm{Cr}$ values can be explained by a kinetic isotope

616 fractionation during loss of $\mathrm{Cr}$ during serpentinization, or by a multistage alteration hypothesis

617 where peridotites lose $\mathrm{Cr}$ via oxidation without significant isotope fractionation in the first stage

618 and then accumulates isotopically heavy $\mathrm{Cr}$ through later-stage sulfate reduction. Significant $\mathrm{Cr}$

619 isotope fractionation during serpentinization indicates that a hydrothermal origin of $\mathrm{Cr}$ must be

620 ruled out before fractioned $\mathrm{Cr}$ in the early sedimentary record can be linked robustly to terrestrial

621 Cr redox cycling.

\section{Acknowledgement}

Funding for this research was provided by Agouron Institute to XLW, National Science Foundation (NSF) EAR-0105927 and EAR-1250269 to JJA, and NSF EAR-1324566 to ES. NJP and CTR acknowledge funding from the Alternative Earths NAI. XLW wishes to thank T.M.

628 basalt samples and Ci Zhang for logistic handling of the Qinling-Tongbai-Dabie samples. JJA 
Vitale Brovarone for samples and discussions, and the Deep Carbon Observatory, and Yale University for support. This research used samples provided by the Ocean Drilling Program (ODP). The authors would like to thank Dr. Catherine Chauvel for editing the paper and three anonymous reviewers for providing constructive comments that greatly improved the quality of the original manuscript.

\section{Figure captions}

Figure 1. A tectonic sketch of the Qinling-Tongbai-Dabie orogen separating the north China block from the south China block. Basalt samples are from South Qinling and eclogite samples are from North Qinling. Detailed geological setting information can be found in Wang et al. (2013) and Ling et al. (2008).

Figure 2. Images for the metacarbonate rock from the Wepawaug Schist. A: A photograph showing the vein intruding the wall rock, generating a reaction aureole. Cal, Ank, Qtz, Ab, Chl, Rt, Ms refer to calcite, ankerite, quartz, albite, chlorite, rutile, and muscovite, respectively. The fluid was associated with regional metamorphism ( $\sim 380-410 \mathrm{Ma})$ during the Acadian orogeny that created the Wepawaug Schist, Connecticut, USA. Details on the geological setting are provided in Ague (2003). The dashed line shows the sampled transect with distance being zero in the center of the vein and increasing toward the right side of the image. B: Mineral assemblage of the vein. Note the calcite rims surrounding the albite grains. C: The contact between the reaction aureole and the vein. Note the pyrite within the aureole. D: Organic matter within the aureole. E: Wallrock with no apparent alteration. F: Albite and chlorite near the contact.

Figure 3. A schematic of the New Albany Shale weathering profile exposed by a road cut near Clay City, Kentucky, USA. The light gray layer represents weathered black shale whereas the darker gray represents deeper layers that are relatively unweathered. Circles represent sampling points. Care was taken to sample from the same horizon to avoid potential syn-depositional variations. Further information can be found in Jaffe et al. (2002).

Figure 4. Location of ODP Hole 504B in the Equatorial Eastern Pacific. On the left is the simplified lithological column in meters below basement (mbbm). Depth in meters below seafloor is also indicated. The basement rock is divided into a volcanic zone, transition zone, and sheeted dike zone. Brecciation is developed in each zone and occurs where alteration is most intensive. Samples with similar characteristics in each section are combined in representative proportions in order to create composite samples. Further information is given in Bach et al. (2004).

Figure 5. Locations of ODP drill cores from the Iberia margin and the $15^{\circ} 20^{\prime} \mathrm{N}$ Mid-AtlanticRidge Fracture Zone, and simplified lithological columns of all the cores from which the investigated serpentinite samples were obtained. Red stars denote sample localities; numbers next to the red stars are $\delta^{53} \mathrm{Cr}$ values $( \pm 0.08 \%$ ). Further information for the cores can be found in Sawyer et al. (1994), Whitmarsh et al., 1998, and Shipboard Scientific Party (2004).

Figure 6. Reproducibility of SRM 979 standard analyzed during this study $(-0.08 \pm 0.05 \%$, 2 SD, $\mathrm{n}=64$ ). The dashed lines represent the $2 \mathrm{SD}$ envelope. Samples are normalized to the average 
$\delta^{53} \mathrm{Cr}$ value of SRM 979 of each session, during which the SRM $979 \delta^{53} \mathrm{Cr}$ variation is typically 677 less than $0.1 \%$.

Figure 7. $\delta^{53} \mathrm{Cr}$ values of high temperature igneous rocks and their metamorphosed equivalents, plotted against their $\mathrm{Cr}$ concentrations. The average $\delta^{53} \mathrm{Cr}$ for fresh silicates $(\mathrm{n}=43)$, metamorphosed silicates $(n=50)$, and chromites $(n=39)$ are $-0.13 \pm 0.13 \% 0$ (2SD), $-0.11 \pm 0.13 \%$

682 (2SD), and $-0.07 \pm 0.13 \%$ (2SD), respectively (data compiled in Table S1). Note that the $\mathrm{x}$-axis is on logarithmic scale.

Figure $8 . \delta^{53} \mathrm{Cr}$ values, $\mathrm{Cr} / \mathrm{Zr}$ ratios, and $\mathrm{K}_{2} \mathrm{O} / \mathrm{Zr}$ ratios for the metacarbonate rock from Wepawaug Schist. The red bar in B indicates upper continental crust $\mathrm{Cr} / \mathrm{Zr}$ ratio. Yellow shaded region denotes the vein and gray shaded region denotes the reaction aureole. The error bars are the external analytical uncertainty ( $0.08 \%$, see 'Methods' section).

Figure $9 . \delta^{53} \mathrm{Cr}$ values, $\mathrm{Cr} / \mathrm{Ti}$ ratios, organic carbon, $\mathrm{Re} / \mathrm{Ti}$ ratios, and $\mathrm{Fe}$ concentration for the New Albany Shale weathering profile. Data other than $\delta^{53} \mathrm{Cr}$ and $\mathrm{Cr} / \mathrm{Ti}$ ratios are from Jaffe et al. (2002). The shaded area in A represents the estimated BSE range (Schoenberg et al., 2008 and Farkas et al., 2013; this study); the shaded area in B represents estimated upper continental crust $\mathrm{Cr} / \mathrm{Ti}$ (Condie, 1993; McLennan, 2001; Rudnick and Gao, 2003). The vertical dashed line shows the boundary of visible weathering.

Figure 10. $\mathrm{Cr} / \mathrm{Ti}$ ratios plotted as a function of iron content. The positive correlation suggests that the $\mathrm{Cr}$ enrichment on the surface of the NAS weathering profile is a result of adsorption of mobile $\mathrm{Cr}(\mathrm{VI})$ to the iron oxides.

Figure 11. $\delta^{53} \mathrm{Cr}$ values and $\mathrm{Cr}$ concentrations for altered oceanic crust composite samples from ODP drill core 504B. The blue shaded region in A denotes the 2SD range around the average $\delta^{53} \mathrm{Cr}$ value of the basalt flows and fresh sheeted dike samples, which we use to represent the least altered oceanic crust; the blue shaded region in $\mathrm{B}$ represents the average $\mathrm{Cr}$ concentration of the same samples. Note that the samples are composite samples and therefore the plotted depth does not represent true depth.

Figure 12. $\delta^{53} \mathrm{Cr}$ values plotted against $\mathrm{Cr}$ concentration for the serpentinite samples examined in this study. The horizontal gray bar denotes $\delta^{53} \mathrm{Cr}$ range for the North Atlantic seawater (Scheiderich et al., 2015); the vertical gray bar denotes the estimated $\mathrm{Cr}$ concentration of the mantle (Sun and McDonough, 1989), which is thought to represent average fresh peridotites. Altered peridotites with heavy $\delta^{53} \mathrm{Cr}$ values have less $\mathrm{Cr}$ than average fresh peridotite, suggesting that the heavy $\delta^{53} \mathrm{Cr}$ values are not a result of direct addition of seawater $\mathrm{Cr}$. The high $\delta^{53} \mathrm{Cr}$ values are possibly due to kinetic isotope fractionation where light isotopes were preferentially lost. The dashed trends are modeled using a Rayleigh fractionation model. The fractionation factors used are $-0.6 \%$ and $-0.17 \%$. The initial $\delta^{53} \mathrm{Cr}$ value used is $-0.2 \%$.

Figure $13 . \delta^{53} \mathrm{Cr}$ values, $\mathrm{Cr}$ concentrations, $\delta^{34} \mathrm{~S}$ values, and sulfur concentrations in the examined serpentinites. The gray and blue bars in A denote $\delta^{53} \mathrm{Cr}$ range for the BSE (Schoenberg et al., 2008 and Farkas et al., 2013; this study) and the North Atlantic seawater (Scheiderich et al., 2015), respectively. The blue bar in B denotes mantle $\mathrm{Cr}$ concentration estimates (Sun and 
McDonough, 1989). Sulfur data are from Alt and Shanks (1998) and Schwarzenbach et al. (2012). Dashed and solid blue lines in C indicate $\delta^{34} \mathrm{~S}$ values for the mantle and modern seawater, respectively (Alt and Shanks, 1998). Blue dashed line in D shows the sulfur concentration of the mantle (McDonough and Sun, 1995).

\section{References}

Ague, J.J., 2002. Gradients in fluid composition across metacarbonate layers of the Wepawaug Schist, Connecticut, USA. Contributions to Mineralogy and Petrology, 143(1): 38-55.

Ague, J.J., 2003. Fluid infiltration and transport of major, minor, and trace elements during regional metamorphism of carbonate rocks, Wepawaug Schist, Connecticut, USA. American Journal of Science, 303(9): 753-816.

Ague, J.J., Eckert, J.O., 2012. Precipitation of rutile and ilmenite needles in garnet: Implications for extreme metamorphic conditions in the Acadian Orogen, USA. American Mineralogist, 97(5-6): 840-855.

Ague, J.J., Eckert, J.O., Chu, X., Baxter, E.F., Chamberlain, C.P., 2013. Discovery of ultrahightemperature metamorphism in the Acadian orogen, Connecticut, USA. Geology, 41(2): 271-274.

Alt, J.C., Honnorez, J., Laverne, C., Emmermann, R., 1986. Hydrothermal alteration of a $1 \mathrm{~km}$ section through the upper oceanic crust, Deep Sea Drilling Project Hole 504B: Mineralogy, chemistry and evolution of seawater - basalt interactions. Journal of Geophysical Research: Solid Earth (1978-2012), 91(B10): 10309-10335.

Alt, J.C., Shanks, W.C., 1998. Sulfur in serpentinized oceanic peridotites: Serpentinization processes and microbial sulfate reduction. Journal of Geophysical Research: Solid Earth (1978-2012), 103(B5): 9917-9929.

Alt, J.C. et al., 2007. Hydrothermal alteration and microbial sulfate reduction in peridotite and gabbro exposed by detachment faulting at the Mid - Atlantic Ridge, $15^{\circ} 20^{\prime} \mathrm{N}$ (ODP Leg 209): A sulfur and oxygen isotope study. Geochemistry, Geophysics, Geosystems, 8: Q08002, doi:10.1029/2007GC001617.

Alt, J.C. et al., 1996. Ridge-flank alteration of upper ocean crust in the eastern Pacific: Synthesis of results for volcanic rocks of Holes 504B and 896A. In: Alt, J.C., Kinoshita, H., Stokking, L.B. (Eds.), Proceedings of the Ocean Drilling Program, Scientific Results, College Station, TX (Ocean Drilling Program), vol. 148, pp. 435-452.

Bach, W., Garrido, C.J., Paulick, H., Harvey, J., Rosner, M., 2004. Seawater - peridotite interactions: First insights from ODP Leg 209, MAR 15 N. Geochemistry, Geophysics, Geosystems, 5: Q09F26, doi:10.1029/2004GC000744.

Bach, W., Peucker-Ehrenbrink, B., Hart, S.R., Blusztajn, J.S., 2003. Geochemistry of hydrothermally altered oceanic crust: DSDP/ODP Hole 504B-Implications for seawatercrust exchange budgets and $\mathrm{Sr}$ and $\mathrm{Pb}$ isotopic evolution of the mantle. Geochemistry, Geophysics, Geosystems, 4: 8904, doi:10.1029/2002GC000419.

Bain, D.J., Bullen, T.D., 2005. Chromium isotope fractionation during oxidation of Cr (III) by manganese oxides. Geochimica et Cosmochimica Acta, 69: S212.

Berger, A., Frei, R., 2014. The fate of chromium during tropical weathering: A laterite profile from Central Madagascar. Geoderma, 213: 521-532.

Berndt, M.E., Allen, D.E., Seyfried, W.E., 1996. Reduction of CO2 during serpentinization of olivine at $300 \mathrm{C}$ and 500 bar. Geology, 24(4): 351-354.

Bigeleisen, J., 1965. Chemistry of isotopes. Science, 147(3657): 463. 
Birck, J.L., Allègre, C.J., 1984. Chromium isotopic anomalies in Allende refractory inclusions. Geophysical Research Letters, 11(10): 943-946.

Bluth, G.J., Kump, L.R., 1991. Phanerozoic paleogeology. Am. J. Sci, 291(3): 284-308.

Bonnand, P., Parkinson, I.J., James, R.H., Karjalainen, A.-M., Fehr, M.A., 2011. Accurate and precise determination of stable $\mathrm{Cr}$ isotope compositions in carbonates by double spike MC-ICP-MS. Journal of Analytical Atomic Spectrometry, 26(3): 528-535.

Broecker, M., Enders, M., 1999. U-Pb zircon geochronology of unusual eclogite-facies rocks from Syros and Tinos (Cyclades, Greece). Geological Magazine, 136(02): 111-118.

Carmichael, I.S., Ghiorso, M.S., 1986. Oxidation-reduction relations in basic magma: a case for homogeneous equilibria. Earth and Planetary Science Letters, 78(2): 200-210.

Carswell, D., Van Roermund, H., de Vries, D.W., 2006. Scandian ultrahigh-pressure metamorphism of proterozoic basement rocks on Fjørtoft and Otrøy, Western Gneiss Region, Norway. International Geology Review, 48(11): 957-977.

Chu, X., Ague, J.J., Axler, J.A., Tian, M., in press. Taconian retrograde eclogite from northwest Connecticut, USA, and its petrotectonic implications. Lithos, doi: 10.1016/j.lithos.2015.10.011.

Condie, K.C., 1993. Chemical composition and evolution of the upper continental crust: contrasting results from surface samples and shales. Chemical Geology, 104(1): 1-37.

Crowe, S.A. et al., 2013. Atmospheric oxygenation three billion years ago. Nature, 501(7468): 535-538.

Dragovic, B., Samanta, L.M., Baxter, E.F., Selverstone, J., 2012. Using garnet to constrain the duration and rate of water-releasing metamorphic reactions during subduction: An example from Sifnos, Greece. Chemical Geology, 314: 9-22.

Eary, L.E., Rai, D., 1987. Kinetics of chromium (III) oxidation to chromium (VI) by reaction with manganese dioxide. Environmental Science \& Technology, 21(12): 1187-1193.

Ellis, A.S., Johnson, T.M., Bullen, T.D., 2002. Chromium isotopes and the fate of hexavalent chromium in the environment. Science, 295(5562): 2060.

Ellis, A.S., Johnson, T.M., Bullen, T.D., 2004. Using chromium stable isotope ratios to quantify $\mathrm{Cr}$ (VI) reduction: lack of sorption effects. Environmental Science \& Technology, 38(13): 3604-3607.

Farkas, J. et al., 2013. Chromium isotope variations $\left(\delta^{53 / 52} \mathrm{Cr}\right)$ in mantle-derived sources and their weathering products: Implications for environmental studies and the evolution of $\delta^{53 / 52} \mathrm{Cr}$ in the Earth's mantle over geologic time. Geochimica et Cosmochimica Acta, 123: 74-92.

Fendorf, S.E., Li, G., 1996. Kinetics of chromate reduction by ferrous iron. Environmental Science \& Technology, 30(5): 1614-1617.

Fendorf, S.E., Zasoski, R.J., 1992. Chromium (III) Oxidation by $\delta$-MnO2. Environmental Science \& Technology, 26(1): 79-85.

Frei, R., Gaucher, C., Poulton, S.W., Canfield, D.E., 2009. Fluctuations in Precambrian atmospheric oxygenation recorded by chromium isotopes. Nature, 461(7261): 250-253.

Frei, R., Poiré, D., Frei, K.M., 2014. Weathering on land and transport of chromium to the ocean in a subtropical region (Misiones, NW Argentina): A chromium stable isotope perspective. Chemical Geology, 381: 110-124.

Frei, R., Polat, A., 2012. Chromium isotope fractionation during oxidative weatheringimplications from the study of a Paleoproterozoic (ca. 1.9 Ga) paleosol, Schreiber Beach, Ontario, Canada. Precambrian Research, 224: 434-453. 
Furry, W., Jones, R.C., Onsager, L., 1939. On the theory of isotope separation by thermal diffusion. Physical Review, 55(11): 1083.

Harwood, D., 1979a. Bedrock geologic map of the Norfolk quadrangle. Connecticut: US Geological Survey Geological Quadrangle Maps of the United States GQ-1518, scale, $1(24,000)$.

Harwood, D.S., 1979b. Geologic map of the South Sandisfield quadrangle, Massachusetts and Connecticut. Seiries Editor,

Huang, F. et al., 2010. Isotope fractionation in silicate melts by thermal diffusion. Nature, 464(7287): 396-400.

Izbicki, J.A., Bullen, T.D., Martin, P., Schroth, B., 2012. Delta Chromium-53/52 isotopic composition of native and contaminated groundwater, Mojave Desert, USA. Applied Geochemistry, 27(4): 841-853.

Jaffe, L.A., Peucker-Ehrenbrink, B., Petsch, S.T., 2002. Mobility of rhenium, platinum group elements and organic carbon during black shale weathering. Earth and Planetary Science Letters, 198(3): 339-353.

Jeandel, C., Minster, J., 1987. Chromium behavior in the ocean: Global versus regional processes. Global Biogeochemical Cycles, 1(2): 131-154.

Keiter, M., Ballhaus, C., Tomaschek, F., 2011. A new geological map of the Island of Syros (Aegean Sea, Greece): Implications for lithostratigraphy and structural history of the Cycladic Blueschist Unit. Geological Society of America Special Papers, 481: 1-43.

Kelley, D.S. et al., 2001. An off-axis hydrothermal vent field near the Mid-Atlantic Ridge at 30 N. Nature, 412(6843): 145-149.

Kelley, D.S. et al., 2005. A serpentinite-hosted ecosystem: the Lost City hydrothermal field. Science, 307(5714): 1428-1434.

Kim, C., Zhou, Q., Deng, B., Thornton, E.C., Xu, H., 2001. Chromium(VI) reduction by hydrogen sulfide in aqueous media: stoichiometry and kinetics. Environmental Science \& Technology, 35(11): 2219-2225.

Konhauser, K.O. et al., 2011. Aerobic bacterial pyrite oxidation and acid rock drainage during the Great Oxidation Event. Nature, 478(7369): 369-373.

Krogh, E., Oh, C., Liou, J., 1994. Polyphase and anticlockwise P - T evolution for Franciscan eclogites and blueschists from Jenner, California, USA. Journal of Metamorphic Geology, 12(2): 121-134.

Lancaster, P.J., Baxter, E.F., Ague, J.J., Breeding, C.M., Owens, T.L., 2008. Synchronous peak Barrovian metamorphism driven by syn - orogenic magmatism and fluid flow in southern Connecticut, USA. Journal of Metamorphic Geology, 26(5): 527-538.

Lanzirotti, A., Hanson, G.N., 1996. Geochronology and geochemistry of multiple generations of monazite from the Wepawaug Schist, Connecticut, USA: implications for monazite stability in metamorphic rocks. Contributions to Mineralogy and Petrology, 125(4): 332340.

Ling, W., Cheng, J., Wang, X., Zhou, H., 2002. Geochemical features of the Neoproterozoic igneous rocks from the Wudang region and their implications for the reconstruction of the Jinning tectonic evolution along the south Qinling orogenic belt. Acta Petrologica Sinica, 18(1): 25-36.

Malavieille, J., Chemenda, A., Larroque, C., 1998. Evolutionary model for Alpine Corsica: mechanism for ophiolite emplacement and exhumation of high-pressure rocks. Terra Nova, 10(6): 317-322. 
Marschall, H.R., Schumacher, J.C., 2012. Arc magmas sourced from mélange diapirs in subduction zones. Nature Geoscience, 5(12): 862-867.

Mayanna, S. et al., 2015. Biogenic precipitation of manganese oxides and enrichment of heavy metals at acidic soil pH. Chemical Geology, 402(0): 6-17.

McDonough, W.F., Sun, S.-S., 1995. The composition of the Earth. Chemical Geology, 120(3): 223-253.

McLennan, S.M., 2001. Relationships between the trace element composition of sedimentary rocks and upper continental crust. Geochemistry, Geophysics, Geosystems, 2(4).

Middelburg, J.J., van der Weijden, C.H., Woittiez, J.R., 1988. Chemical processes affecting the mobility of major, minor and trace elements during weathering of granitic rocks. Chemical Geology, 68(3): 253-273.

Miller, C.A., Peucker-Ehrenbrink, B., Schauble, E.A., 2015. Theoretical modeling of rhenium isotope fractionation, natural variations across a black shale weathering profile, and potential as a paleoredox proxy. Earth and Planetary Science Letters, 430: 339-348.

Moynier, F., Yin, Q.-Z., Schauble, E., 2011. Isotopic evidence of Cr partitioning into Earth's core. Science, 331(6023): 1417-1420.

Page, F.Z., Armstrong, L.S., Essene, E.J., Mukasa, S.B., 2007. Prograde and retrograde history of the Junction School eclogite, California, and an evaluation of garnet-phengiteclinopyroxene thermobarometry. Contributions to Mineralogy and Petrology, 153(5): 533-555.

Papanastassiou, D., 1986. Chromium isotopic anomalies in the Allende meteorite. The Astrophysical Journal, 308: L27-L30.

Parsons, B., 1981. The rates of plate creation and consumption. Geophysical Journal International, 67(2): 437-448.

Paulick, H. et al., 2006. Geochemistry of abyssal peridotites (Mid-Atlantic Ridge, 15²0' N, ODP Leg 209): implications for fluid/rock interaction in slow spreading environments. Chemical Geology, 234(3): 179-210.

Petsch, S., Berner, R., Eglinton, T., 2000. A field study of the chemical weathering of ancient sedimentary organic matter. Organic Geochemistry, 31(5): 475-487.

Petsch, S., Eglinton, T., Edwards, K., 2001 a. ${ }^{14} \mathrm{C}$-dead living biomass: evidence for microbial assimilation of ancient organic carbon during shale weathering. Science, 292(5519): 1127-1131.

Petsch, S.T., Smernik, R., Eglinton, T., Oades, J., 2001b. A solid state ${ }^{13}$ C-NMR study of kerogen degradation during black shale weathering. Geochimica et Cosmochimica Acta, 65(12): 1867-1882.

Pettine, M., D'Ottone, L., Campanella, L., Millero, F.J., Passino, R., 1998. The reduction of chromium (VI) by iron (II) in aqueous solutions. Geochimica et Cosmochimica Acta, 62(9): 1509-1519.

Planavsky, N.J. et al., 2014. Low Mid-Proterozoic atmospheric oxygen levels and the delayed rise of animals. Science, 346(6209): 635-638.

Podosek, F. et al., 1997. Thoroughly anomalous chromium in Orgueil. Meteoritics \& Planetary Science, 32(5): 617-627.

Qin, L. et al., 2011. Extreme ${ }^{54} \mathrm{Cr}$-rich nano-oxides in the CI chondrite Orgueil-Implication for a late supernova injection into the solar system. Geochimica et Cosmochimica Acta, 75(2): 629-644. 
904

905

906

907

908

909

910

911

912

913

914

915

916

917

918

919

920

921

922

923

924

925

926

927

928

929

930

931

932

933

934

935

936

937

938

939

940

941

942

943

944

945

946

947

948

949

Qin, L., Xia, J., Carlson, R., Zhang, Q., 2015. Chromium Stable Isotope Composition of Meteorites, Lunar and Planetary Science Conference.

Rai, D., Eary, L., Zachara, J., 1989. Environmental chemistry of chromium. Science of the Total Environment, 86(1-2): 15-23.

Rai, D., Sass, B.M., Moore, D.A., 1987. Chromium(III) hydrolysis constants and solubility of chromium(III) hydroxide. Inorganic Chemistry, 26(3): 345-349.

Ratschbacher, L. et al., 2003. Tectonics of the Qinling (Central China): tectonostratigraphy, geochronology, and deformation history. Tectonophysics, 366(1-2): 1-53.

Reinhard, C.T. et al., 2013. Proterozoic ocean redox and biogeochemical stasis. Proceedings of the National Academy of Sciences of the United States of America, 110(14): 5357-5362.

Reinhard, C.T. et al., 2014. The isotopic composition of authigenic chromium in anoxic marine sediments: A case study from the Cariaco Basin. Earth and Planetary Science Letters, 407: 9-18.

Richter, F.M., Watson, E.B., Mendybaev, R.A., Teng, F.-Z., Janney, P.E., 2008. Magnesium isotope fractionation in silicate melts by chemical and thermal diffusion. Geochimica et Cosmochimica Acta, 72(1): 206-220.

Rotaru, M., Birck, J.L., Allegre, C.J., 1992. Clues to early solar system history from chromium isotopes in carbonaceous chondrites. Nature, 358: 465-470.

Rudnick, R.L., Gao, S., 2003. Composition of the Continental Crust. In: Turekian, H.D.H.K. (Ed.), Treatise on Geochemistry, Pergamon, Oxford, vol. 3, pp. 1-64.

Sawyer, D., Whitmarsh, R., Klaus, A., 1994. Iberia Abyssal Plain Sites 897-901, Proceedings of the Ocean Drilling Program, Initial Reports, College Station, TX (Ocean Drilling Program), vol. 149.

Schauble, E., Rossman, G.R., Taylor, H.P., Jr, 2004. Theoretical estimates of equilibrium chromium-isotope fractionations. Chemical Geology, 205(1-2): 99-114.

Schauble, E.A., 2007. Role of nuclear volume in driving equilibrium stable isotope fractionation of mercury, thallium, and other very heavy elements. Geochimica et Cosmochimica Acta, 71(9): 2170-2189.

Scheiderich, K., Amini, M., Holmden, C., Francois, R., 2015. Global variability of chromium isotopes in seawater demonstrated by Pacific, Atlantic, and Arctic Ocean samples. Earth and Planetary Science Letters, 423: 87-97.

Schoenberg, R., Zink, S., Staubwasser, M., von Blanckenburg, F., 2008. The stable Cr isotope inventory of solid Earth reservoirs determined by double spike MC-ICP-MS. Chemical Geology, 249(3-4): 294-306.

Schwarzenbach, E.M., Frueh-Green, G.L., Bernasconi, S.M., Alt, J.C., Plas, A., 2013. Serpentinization and carbon sequestration: A study of two ancient peridotite-hosted hydrothermal systems. Chemical Geology, 351: 115-133.

Schwarzenbach, E.M. et al., 2012. Sulfur geochemistry of peridotite-hosted hydrothermal systems: comparing the Ligurian ophiolites with oceanic serpentinites. Geochimica et Cosmochimica Acta, 91: 283-305.

Seyfried, W., Foustoukos, D., Fu, Q., 2007. Redox evolution and mass transfer during serpentinization: An experimental and theoretical study at $200^{\circ} \mathrm{C}, 500 \mathrm{bar}$ with implications for ultramafic-hosted hydrothermal systems at Mid-Ocean Ridges. Geochimica et Cosmochimica Acta, 71(15): 3872-3886.

Shen, J. et al., 2015. Chromium isotope signature during continental crust subduction recorded in metamorphic rocks. Geochemistry, Geophysics, Geosystems, 16. 
Shipboard Scientific Party, 2004. Leg 209 summary. In: Kelemen, P., Kikawa, E., Miller, D., al., e. (Eds.), Proceedings of the Ocean Drilling Program, Initial Reports, College Station, TX (Ocean Drilling Program), vol. 209, pp. 1-139.

Shukolyukov, A., Lugmair, G., 2006. Manganese-chromium isotope systematics of carbonaceous chondrites. Earth and Planetary Science Letters, 250(1): 200-213.

Staudigel, H., 2014. Chemical Fluxes from Hydrothermal Alteration of the Oceanic Crust. In: Turekian, H.D.H.K. (Ed.), Treatise on Geochemistry (Second Edition), Elsevier, Oxford, vol. 4, pp. 583-606.

Sullivan, P.J., Yelton, J.L., Reddy, K., 1988. Iron sulfide oxidation and the chemistry of acid generation. Environmental Geology and Water Sciences, 11(3): 289-295.

Sun, S.-S., McDonough, W., 1989. Chemical and isotopic systematics of oceanic basalts: implications for mantle composition and processes. Geological Society, London, Special Publications, 42(1): 313-345.

Tebo, B.M. et al., 2004. Biogenic manganese oxides: properties and mechanisms of formation. Annual Review of Earth and Planetary Sciences, 32: 287-328.

Terry, M.P., Robinson, P., Ravna, E.J.K., 2000. Kyanite eclogite thermobarometry and evidence for thrusting of UHP over HP metamorphic rocks, Nordøyane, Western Gneiss Region, Norway. American Mineralogist, 85(11-12): 1637-1650.

Trinquier, A., Birck, J.-L., Allègre, C.J., 2007. Widespread ${ }^{54} \mathrm{Cr}$ heterogeneity in the inner solar system. The Astrophysical Journal, 655(2): 1179-1185.

Trinquier, A., Birck, J.-L., Allègre, C.J., 2008. High-precision analysis of chromium isotopes in terrestrial and meteorite samples by thermal ionization mass spectrometry. Journal of Analytical Atomic Spectrometry, 23(12): 1565-1574.

Trotet, F., Vidal, O., Jolivet, L., 2001. Exhumation of Syros and Sifnos metamorphic rocks (Cyclades, Greece). New constraints on the PT paths. European Journal of Mineralogy, 13(5): 901-902.

Van der Weijden, C., van der Weijden, R.D., 1995. Mobility of major, minor and some redoxsensitive trace elements and rare-earth elements during weathering of four granitoids in central Portugal. Chemical Geology, 125(3): 149-167.

Vital Brovarone, A., Groppo, C., Hetenyi, G., Compagnoni, R., Malavieille, J., 2011. Coexistence of lawsonite - bearing eclogite and blueschist: phase equilibria modelling of Alpine Corsica metabasalts and petrological evolution of subducting slabs. Journal of Metamorphic Geology, 29(5): 583-600.

Wakabayashi, J., 1999. The Franciscan: California's classic subduction complex. Geological Society of America Special Papers, 338: 111-121.

Wang, H. et al., 2013. Continental origin of eclogites in the North Qinling terrane and its tectonic implications. Precambrian Research, 230: 13-30.

Wang, X.L., Johnson, T.M., Ellis, A.S., 2015a. Equilibrium Isotopic Fractionation and Isotopic Exchange Kinetics between $\mathrm{Cr}$ (III) and Cr (VI). Geochimica et Cosmochimica Acta, 153: 72-90.

Wang, X.L., Johnson, T.M., Lundstrom, C.C., 2015b. Isotope fractionation during oxidation of tetravalent uranium by dissolved oxygen. Geochimica et Cosmochimica Acta, 150(0): 160-170.

Wanner, C., Eggenberger, U., Kurz, D., Zink, S., Mäder, U., 2011. A chromate-contaminated site in southern Switzerland, part 1: Site characterization and the use of Cr isotopes to delineate fate and transport. Applied Geochemistry, 27: 644-654. 
996 Whitmarsh, R.B., Beslier, M.-O., Wallace, P.J., 1998. Return to Iberia Sites 1065-1070, Drilling Program), vol. 173. between $\mathrm{Cr}(\mathrm{III})$ and $\mathrm{Cr}(\mathrm{VI})$ in aqueous media. Geochimica et Cosmochimica Acta, 74: 5729-5745. 
Table 1. Basic information and results for all samples examined in this study.

1004

\begin{tabular}{|c|c|c|c|c|c|c|c|c|}
\hline & Sample ID & Location & Literature & $\begin{array}{l}\text { Distance from } \\
\text { surface }(\mathbf{m})\end{array}$ & $\begin{array}{l}{[\mathrm{Cr}]} \\
(\mathrm{ug} / \mathrm{g}) *\end{array}$ & $\begin{array}{l}\delta^{53} \mathrm{Cr} \\
(\% 0)\end{array}$ & $\begin{array}{l}\text { error } \\
(\%) * *\end{array}$ & $\mathbf{n} * * *$ \\
\hline \multirow[t]{10}{*}{ NAS shale } & NAS0 & Kentucky, USA & Jaffe et al., 2002 & 0.00 & 107.4 & 0.47 & 0.08 & 2 \\
\hline & NAS3 & " & " & 0.91 & 93.6 & 0.13 & 0.08 & 2 \\
\hline & NAS8 & $"$ & $"$ & 2.44 & 89.1 & 0.17 & 0.08 & 2 \\
\hline & NAS14 & $"$ & $"$ & 4.27 & 77.3 & 0.15 & 0.08 & 2 \\
\hline & NAS20 & " & $"$ & 6.10 & 74.5 & -0.53 & 0.08 & 2 \\
\hline & NAS26 & $"$ & $"$ & 7.92 & 73.0 & 0.07 & 0.08 & 2 \\
\hline & NAS36 & $"$ & $"$ & 10.97 & 72.8 & 0.00 & 0.08 & 2 \\
\hline & NAS46 & $"$ & $"$ & 14.02 & 71.1 & 0.02 & 0.08 & 2 \\
\hline & & & & $\begin{array}{l}\text { Depth } \\
(\text { mbsf) } * * * *\end{array}$ & & & & \\
\hline & $1268 \mathrm{~A}-1$ & $\begin{array}{l}\text { MAR } 15^{\circ} 20^{\prime} \\
\text { fraction zone }\end{array}$ & Paulick et al., 2006 & 35.4 & 883.3 & -0.02 & 0.08 & 1 \\
\hline \multirow{19}{*}{ Serpentinite } & $1268 \mathrm{~A}-2$ & " & " & 82.1 & 1153.6 & 0.06 & 0.08 & 1 \\
\hline & $1272 \mathrm{~A}-5$ & $"$ & Bach et al., 2004 & 99.4 & 1168.5 & 0.04 & 0.08 & 1 \\
\hline & $1272 \mathrm{~A}-6$ & $"$ & $"$ & 107.5 & 792.0 & 0.25 & 0.08 & 1 \\
\hline & & & Schwarzenbach et al., & & & & & \\
\hline & 1070A-1 & Iberian Margin & 2012 & 705.6 & 1250.6 & 0.26 & 0.08 & 2 \\
\hline & $1070 \mathrm{~A}-2$ & $"$ & $"$ & 706.3 & 1692.4 & 0.09 & 0.08 & 1 \\
\hline & $1070 \mathrm{~A}-3$ & $"$ & $"$ & 707.02 & 1253.3 & 0.09 & 0.08 & 1 \\
\hline & 1070A-3- & & & & & & & \\
\hline & $\mathrm{dc}^{* * * * *}$ & $"$ & $"$ & $"$ & $"$ & 0.10 & 0.08 & 1 \\
\hline & & & Schwarzenbach et al., & & & & & \\
\hline & 897C-3 & $"$ & 2013 & 680 & 858.5 & 0.52 & 0.08 & 1 \\
\hline & $897 \mathrm{C}-3-\mathrm{dc}$ & $"$ & $"$ & $"$ & $"$ & 0.51 & 0.08 & 1 \\
\hline & 897C-7 & $"$ & $"$ & 710 & 595.5 & 0.10 & 0.08 & 1 \\
\hline & 897D-9 & $"$ & $"$ & 742.2 & 659.0 & 0.14 & 0.08 & 1 \\
\hline & 897D-13 & $"$ & $"$ & 773 & 980.2 & 0.20 & 0.08 & 1 \\
\hline & LA3a & Cava dei Marmi & $\begin{array}{l}\text { Schwarzenbach et al., } \\
2012\end{array}$ & & 1604.4 & -0.11 & 0.08 & 1 \\
\hline & LA20a & $"$ & $"$ & & 1717.5 & 0.12 & 0.08 & 1 \\
\hline & LM027 & Cava Montaretto & " & & 1951.7 & -0.15 & 0.08 & 1 \\
\hline & LM027-dc & $"$ & $"$ & & " & -0.13 & 0.08 & 1 \\
\hline
\end{tabular}




$\begin{array}{lll} & & 37^{\circ} 29.607^{\prime} \mathrm{N}, 24^{\circ} \\ \text { JAGSY12A } & \text { Syros, Greece } & 54.556^{\prime} \mathrm{E} \\ \text { JAGSY12A-dc } & " & " \\ \text { JAGSY12A- } & & " \\ \text { dd } * * * *^{* * *} & " & 37^{\circ} 29.421^{\prime} \mathrm{N}, 24^{\circ} \\ & & 54.078^{\prime} \mathrm{E} \\ \text { JAGSY13C } & " & \text { Marschall et al., } 2012 \\ \text { JAGSY8A-2 } & " & \end{array}$

$\begin{array}{llll}\begin{array}{l}\text { Altered oceanic } \\ \text { crust }\end{array} & \text { Equitorial East } & \\ & \text { VZP } & \text { Pacific } & \text { Bach et al., } 2003 \\ \text { VZM } & " & " \\ \text { VZB } & " & " \\ \text { TZP } & " & " \\ \text { TZM } & " & " \\ \text { TZM-dc } & " & " \\ \text { SDCB } & " & "\end{array}$

MetaCarbonate

$\begin{array}{lll}\text { JAW-197 AS } & \text { Connecticut, USA } & \text { Ague, } 2003 \\ \text { JAW-197 AS-dc } & " & " \\ \text { JAW-197 Ai } & " & " \\ \text { JAW-197 Aii } & " & " \\ \text { JAW-197 Aiii } & " & \\ \text { JAW-197 Aiii- } & " & " \\ \text { dc } & " & "\end{array}$

\section{Mafic/Metamafi} c

$\begin{array}{lll}\text { WD05-02 } & \text { Hubei, China } & \text { Ling et al., } 2008 \\ \text { WD05-07 } & " & " \\ \text { WD05-10 } & " & " \\ \text { WD05-11 } & " & " \\ \text { WD05-23 } & " & \end{array}$

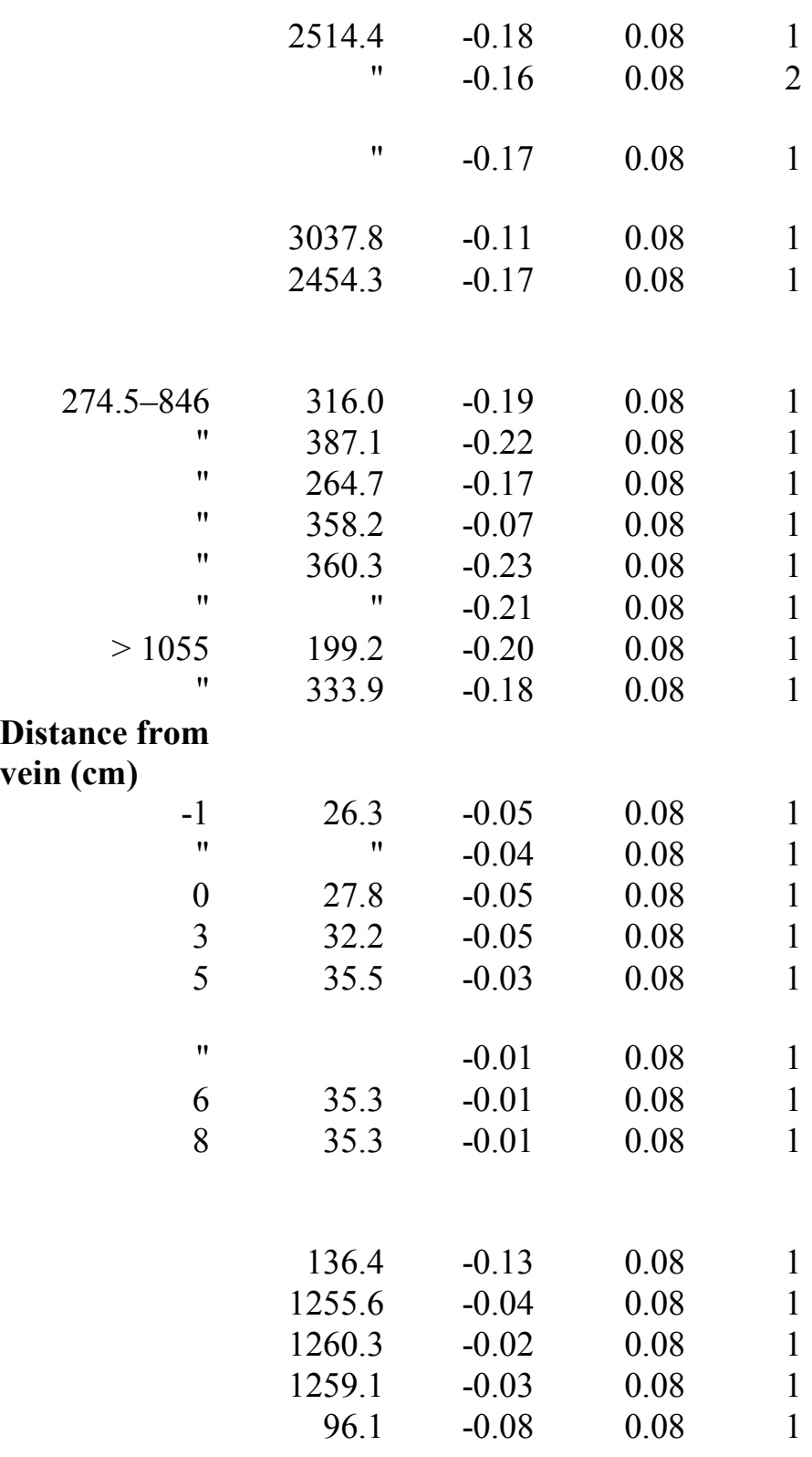




\begin{tabular}{|c|c|c|c|c|c|c|}
\hline WD06-52 & $"$ & $"$ & 335.6 & -0.12 & 0.08 & 1 \\
\hline WD05-54 & $"$ & $"$ & 148.8 & -0.21 & 0.08 & 1 \\
\hline WD05-56 & $"$ & $"$ & 162.2 & -0.20 & 0.08 & 1 \\
\hline WD05-61 & $"$ & $"$ & 224.3 & -0.19 & 0.08 & 1 \\
\hline WD05-63 & $"$ & $"$ & 131.3 & -0.13 & 0.08 & 1 \\
\hline 10QL136 & Henan, China & Wang et al., 2013 & 158.1 & -0.10 & 0.08 & 1 \\
\hline 10QL137 & " & " & 153.6 & -0.11 & 0.08 & 1 \\
\hline 10QL138 & $"$ & $"$ & 51.9 & -0.01 & 0.08 & 1 \\
\hline 10QL139 & $"$ & $"$ & 126.8 & -0.10 & 0.08 & 1 \\
\hline 10QL140 & $"$ & $"$ & 163.3 & -0.08 & 0.08 & 2 \\
\hline 10QL141 & $"$ & $"$ & 119.9 & -0.08 & 0.08 & 1 \\
\hline 10QL144 & $"$ & $"$ & 100.8 & -0.10 & 0.08 & 1 \\
\hline 10QL145 & $"$ & $"$ & 48.2 & -0.08 & 0.08 & 2 \\
\hline 10QL147 & $"$ & $"$ & 48.0 & -0.08 & 0.08 & 1 \\
\hline 10QL149 & $"$ & $"$ & 93.2 & -0.06 & 0.08 & 1 \\
\hline $\mathrm{CRB}$ & Farinole, Corsica & Vitale Brovarone, 2011 & 404.6 & -0.22 & 0.08 & 1 \\
\hline CRB-dc & " & " & " & -0.21 & 0.08 & 1 \\
\hline JAGTI-1A & Tinos, Greece & $\begin{array}{l}\text { Broecker and Enders, } \\
1999 \\
37^{\circ} 26.660^{\prime} \mathrm{N}, 24^{\circ}\end{array}$ & 62.5 & -0.08 & 0.08 & 2 \\
\hline JAGSY-58A & Syros, Greece & $\begin{array}{l}53.327^{\prime} \mathrm{E} \\
41^{\circ} 52.423^{\prime} \mathrm{N}, 72^{\circ}\end{array}$ & 1576.6 & -0.24 & 0.08 & 1 \\
\hline JAQ158A & Connecticut, USA & $16.335^{\prime} \mathrm{W}$ & 663.3 & -0.08 & 0.08 & 2 \\
\hline JANW-17 & Connecticut, USA & Harwood, 1979a, b & 50.1 & -0.17 & 0.08 & 1 \\
\hline CBJB2 & California, USA & Krogh et al., 1994 & 65.5 & -0.16 & 0.08 & 1 \\
\hline 6001 & " & Page et al., 2007 & 120.8 & -0.20 & 0.08 & 1 \\
\hline $6001-\mathrm{dc}$ & $"$ & " & " & -0.14 & 0.08 & 2 \\
\hline $4-1$ & Norway & Terry et al., 2000 & 498.8 & -0.22 & 0.08 & 1 \\
\hline
\end{tabular}

* Based on isotope dilution.

** 2 standard deviation of NIST SRM 3112a and USGS BHVO-2 that went through the same chemical procedures as samples.

$* * *$ remeasurement of the same purified sample solution

**** meters below seafloor

*****'dc' represents duplicated column chemistry; 'dd' represent duplicated digestion+column chemistry. 


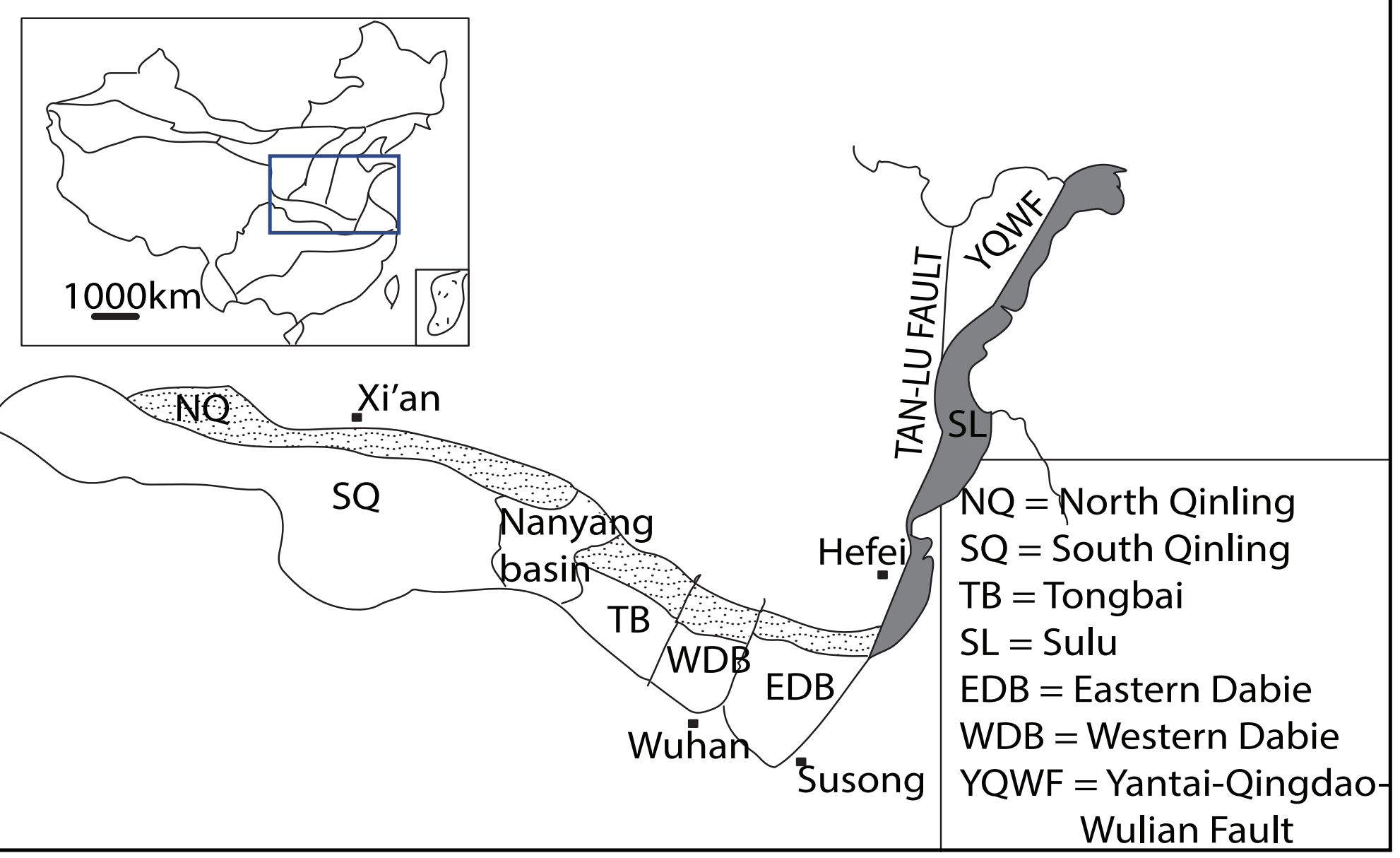



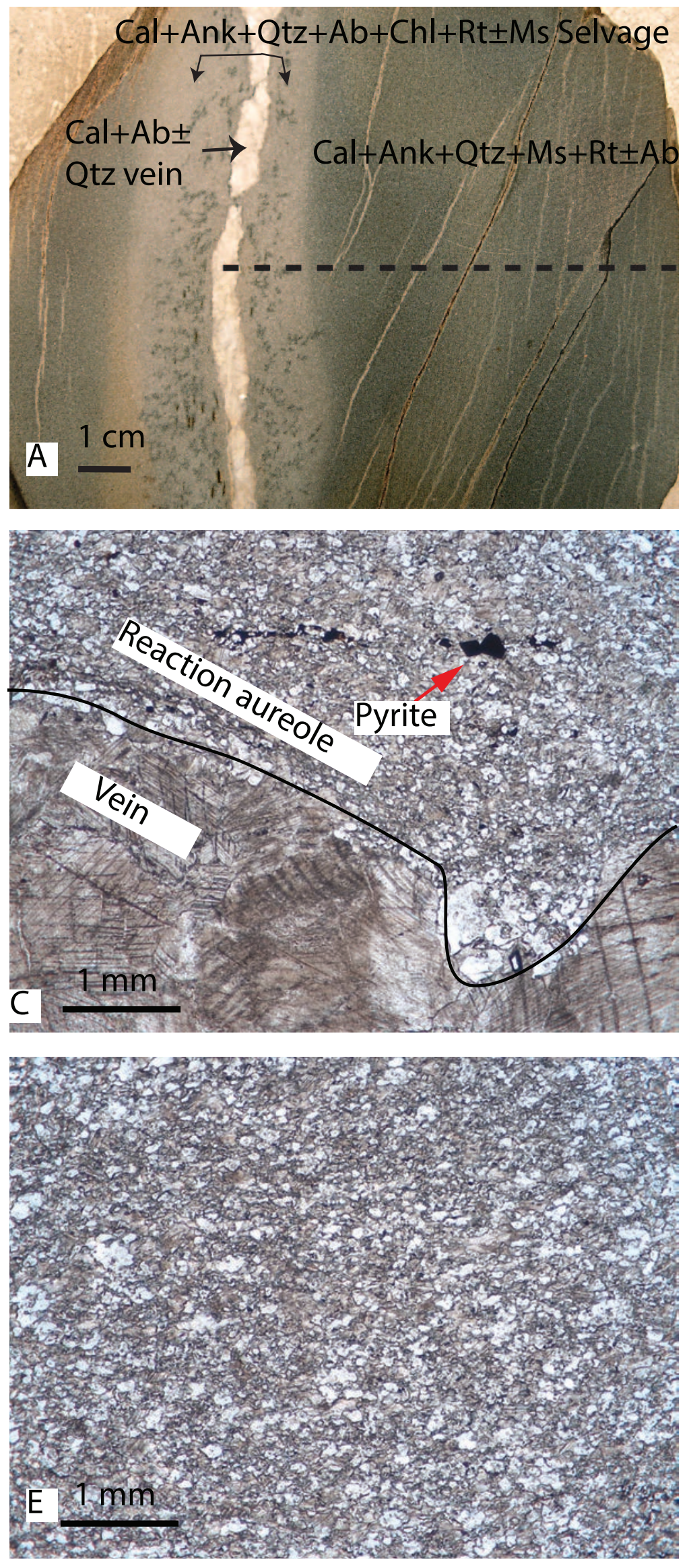
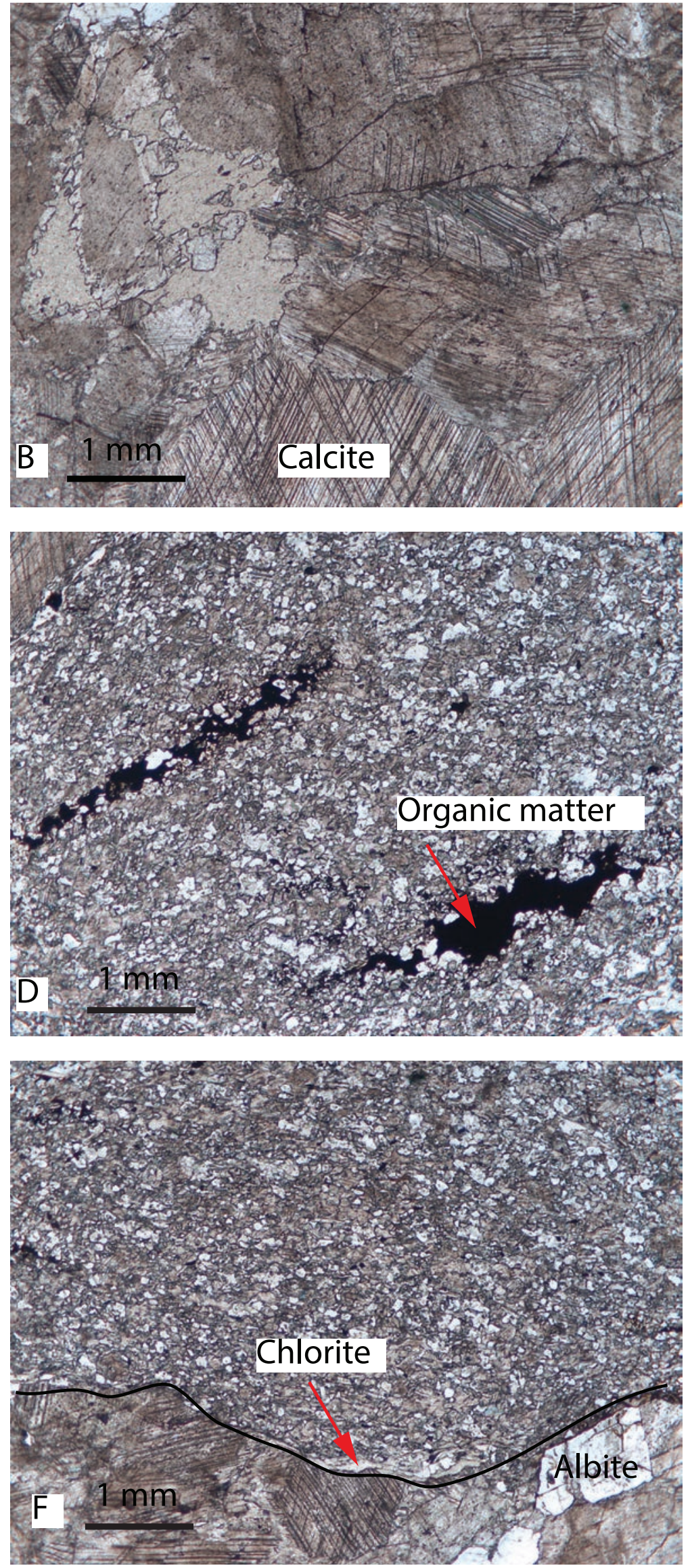


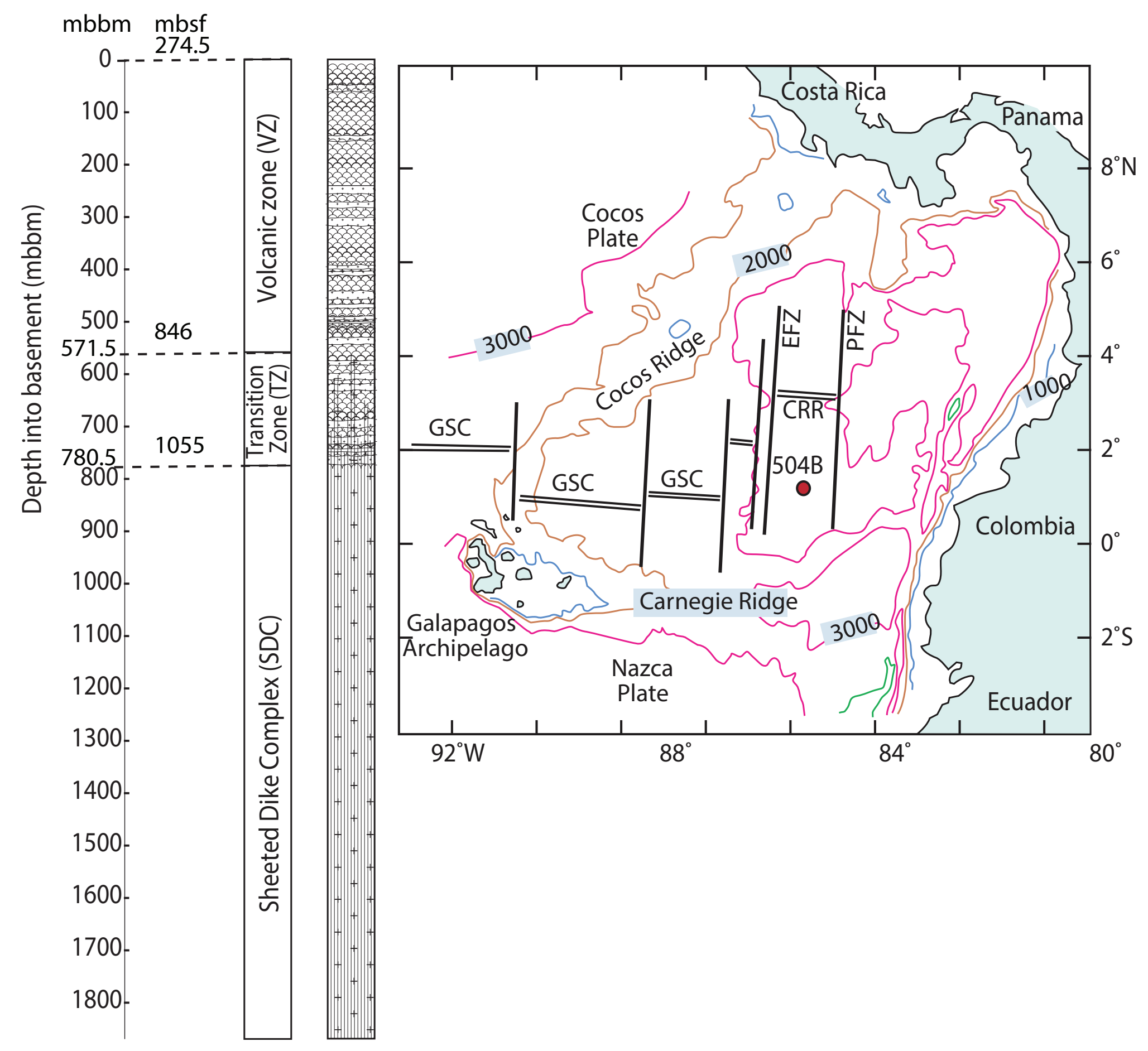




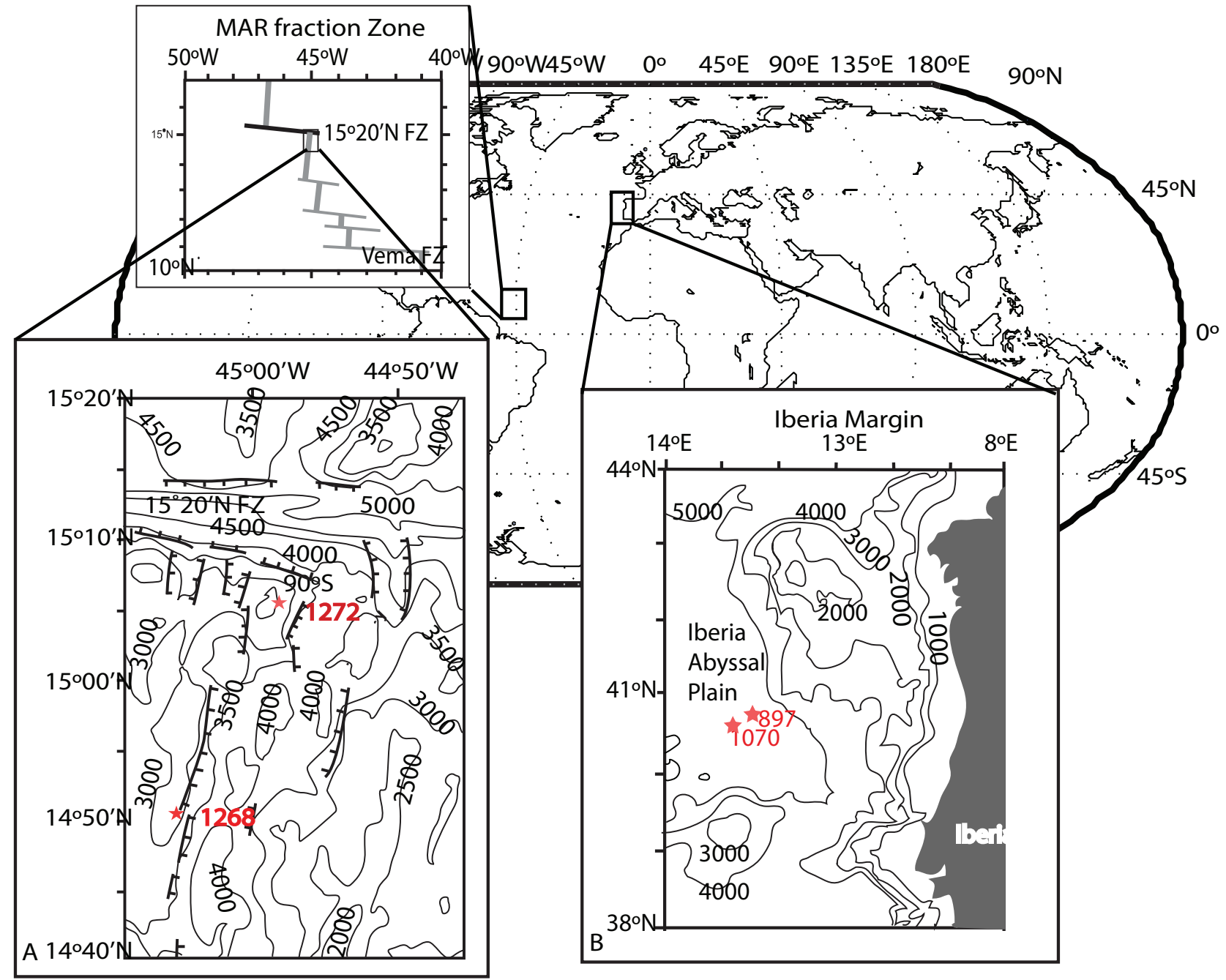

Hole 1268A Hole 1272A

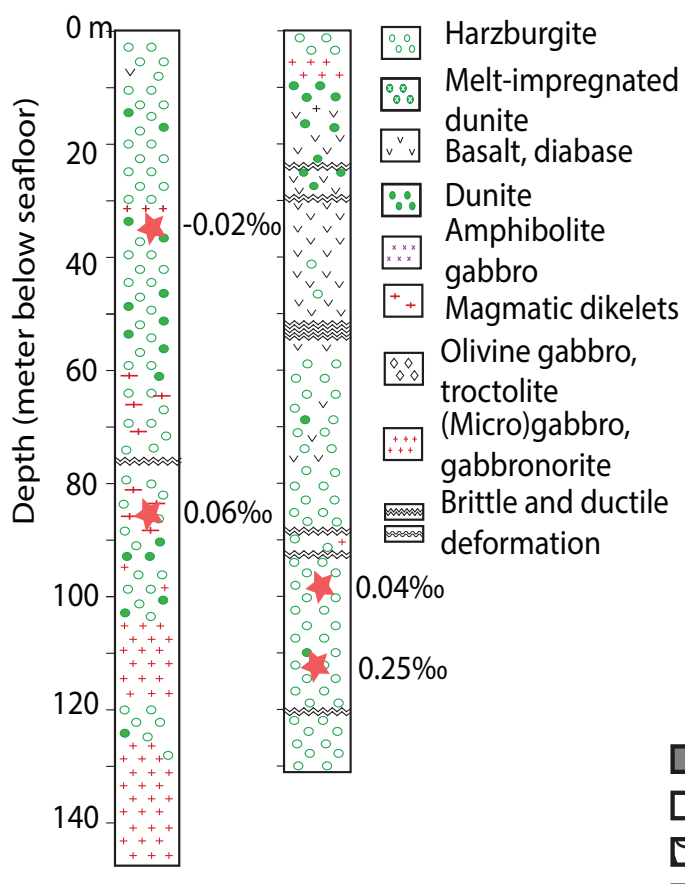

$897 C$

897D

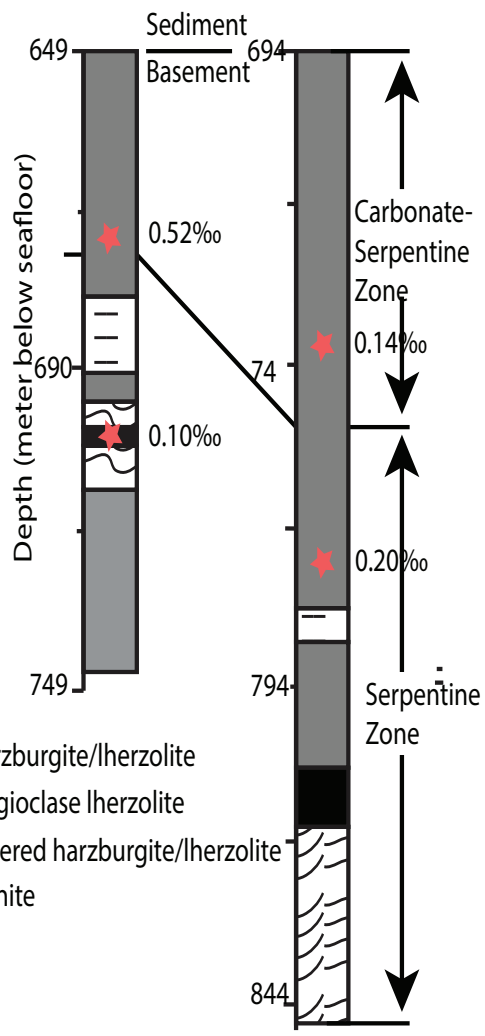

Hole 1070A

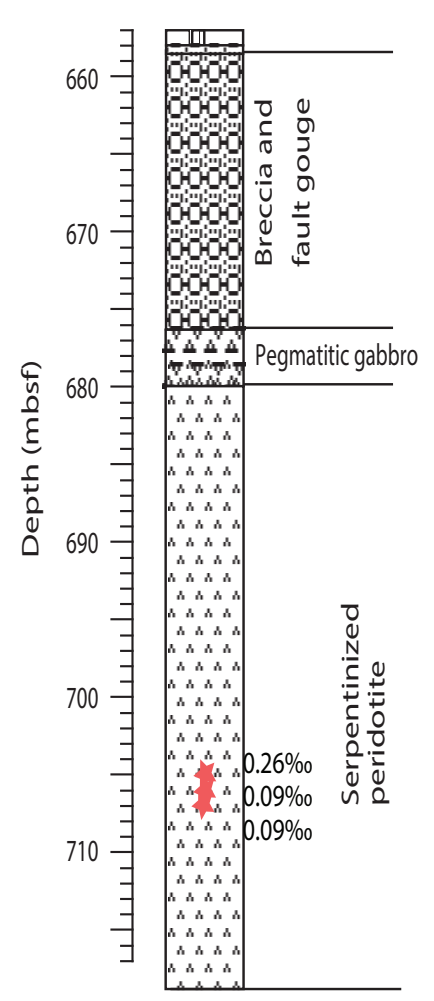




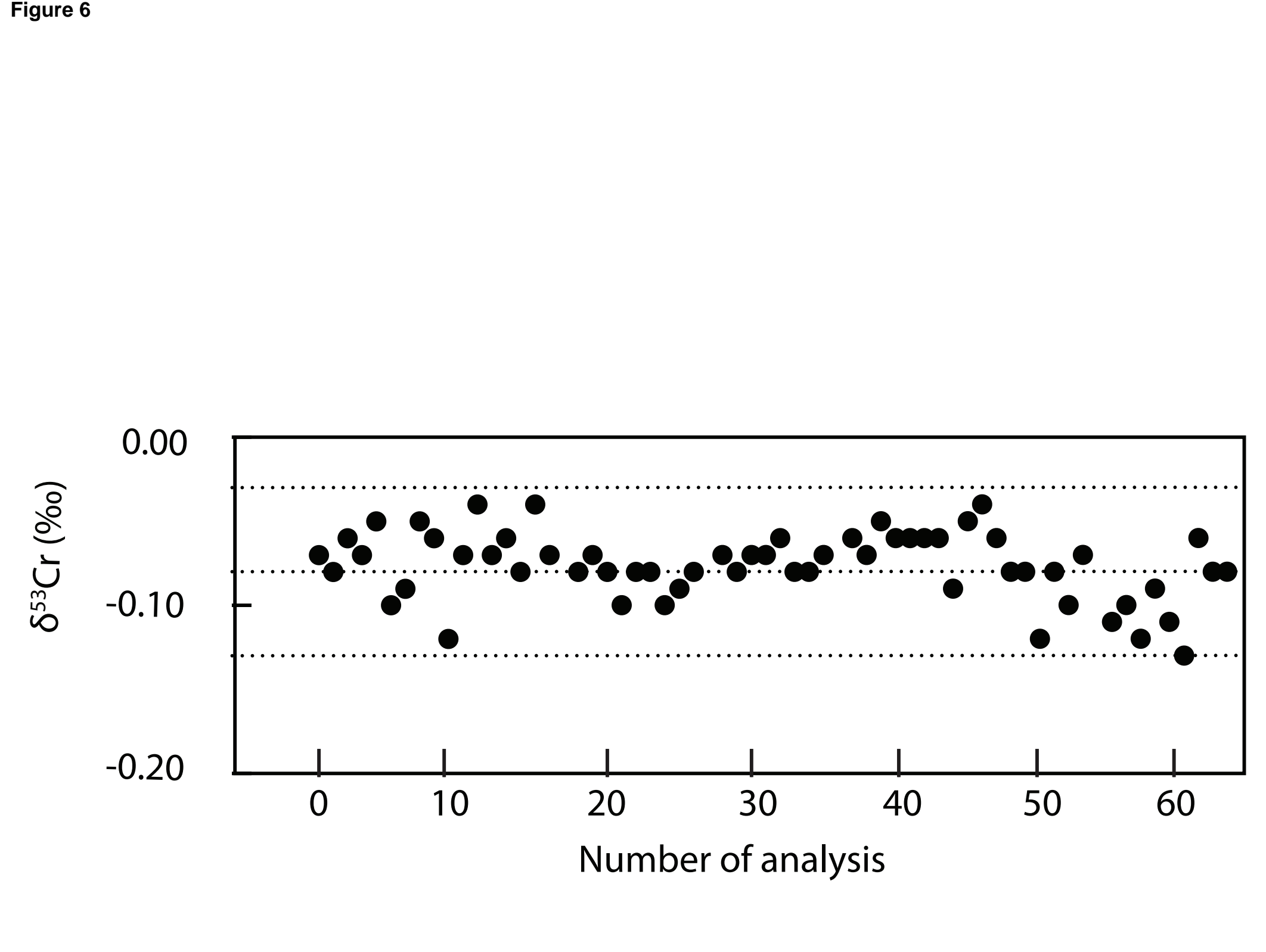

Figure 6

(

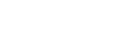

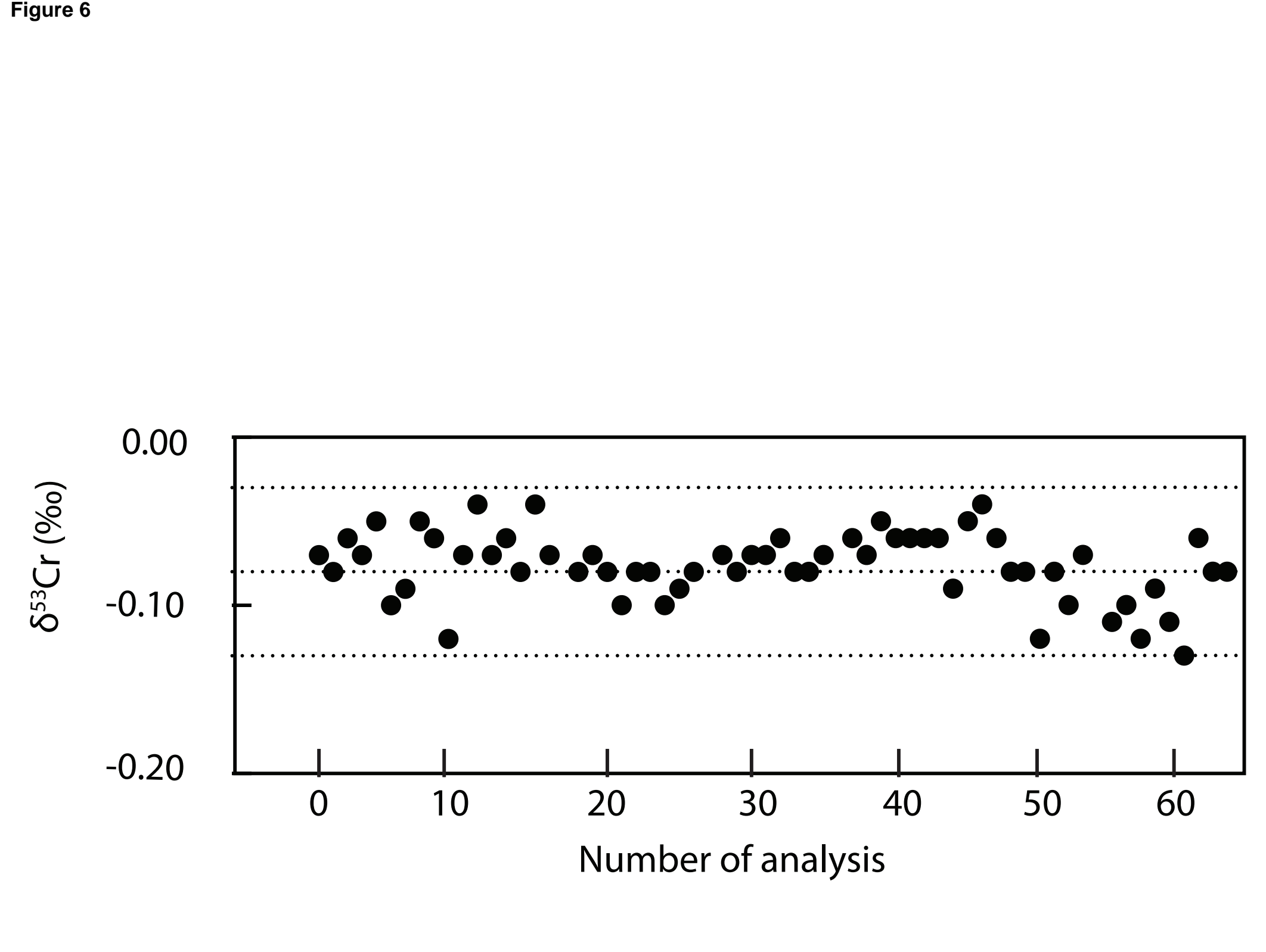

6

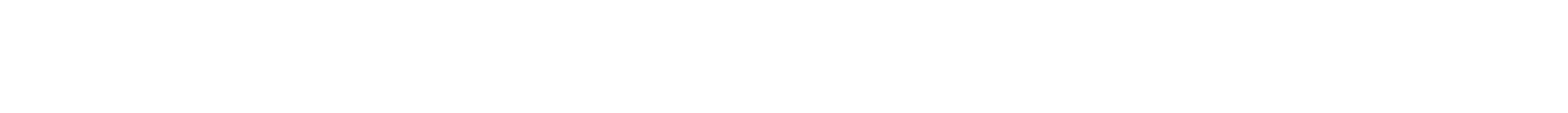




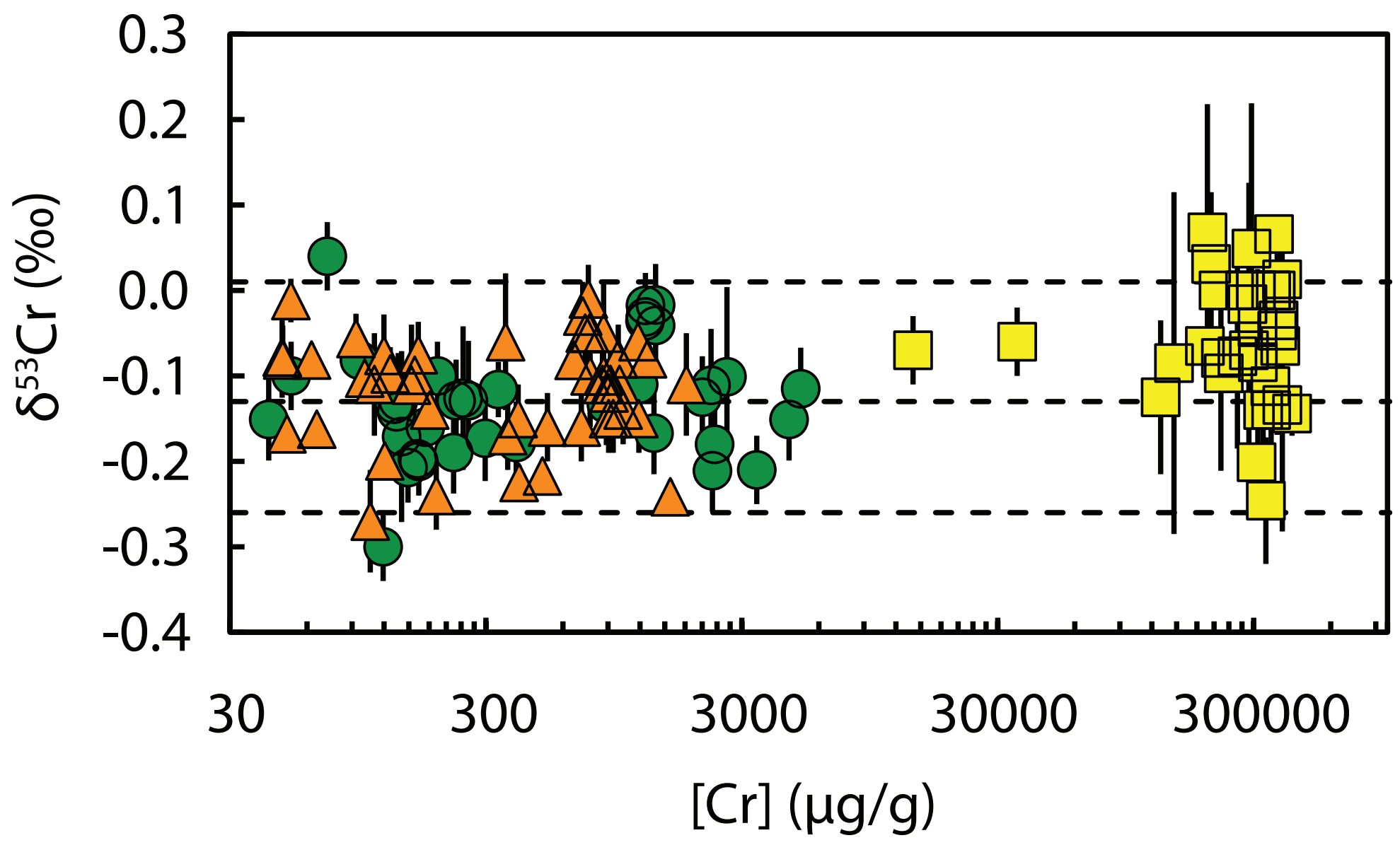

OFresh silicate $\quad \Delta$ Metamorphosed silicate 口Chromite $\left(\mathrm{FeMgCr}_{2} \mathrm{O}_{4}\right)$ 

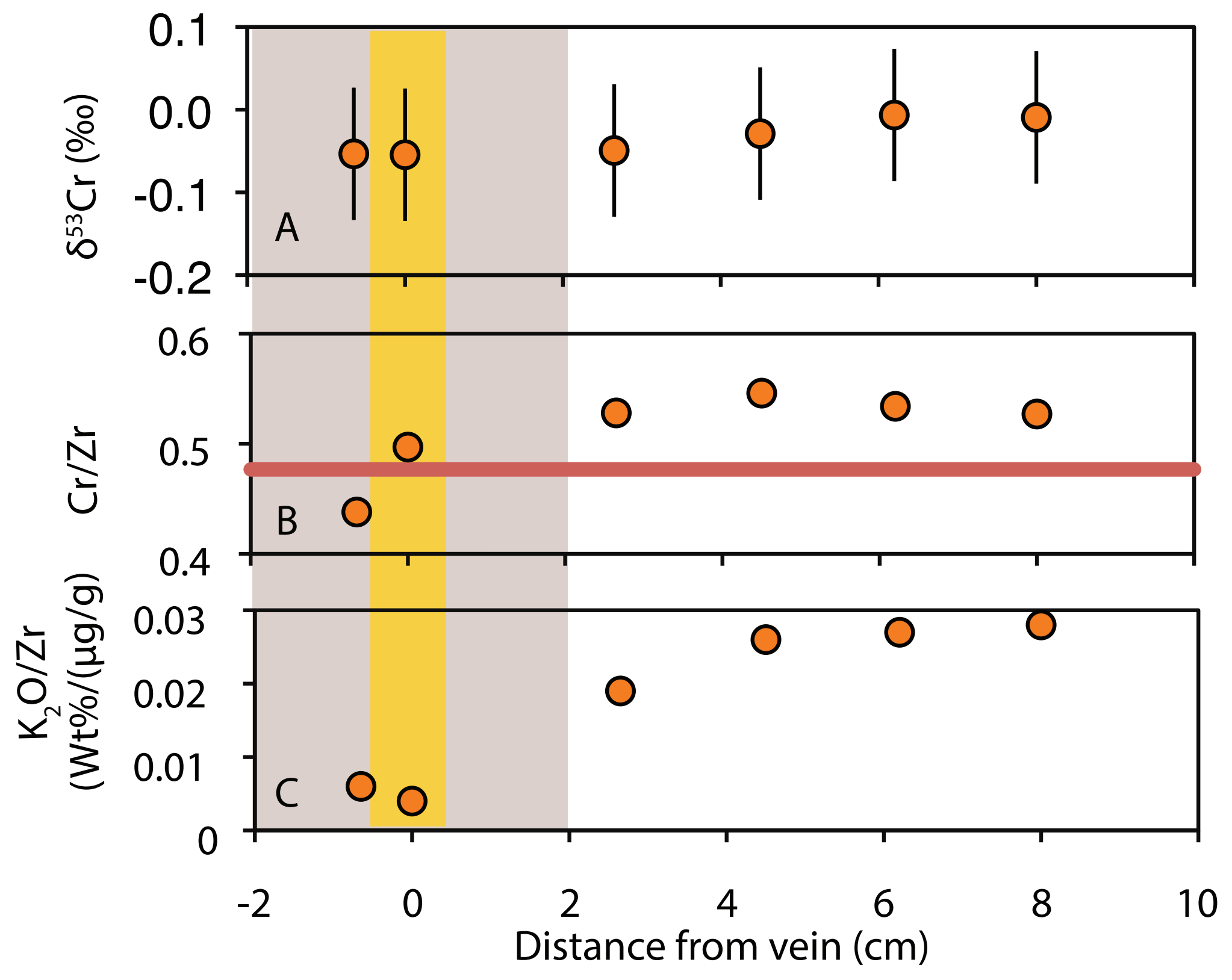

$\square$ vein $\square$ Altered $\square$ Unaltered 
Figure 9

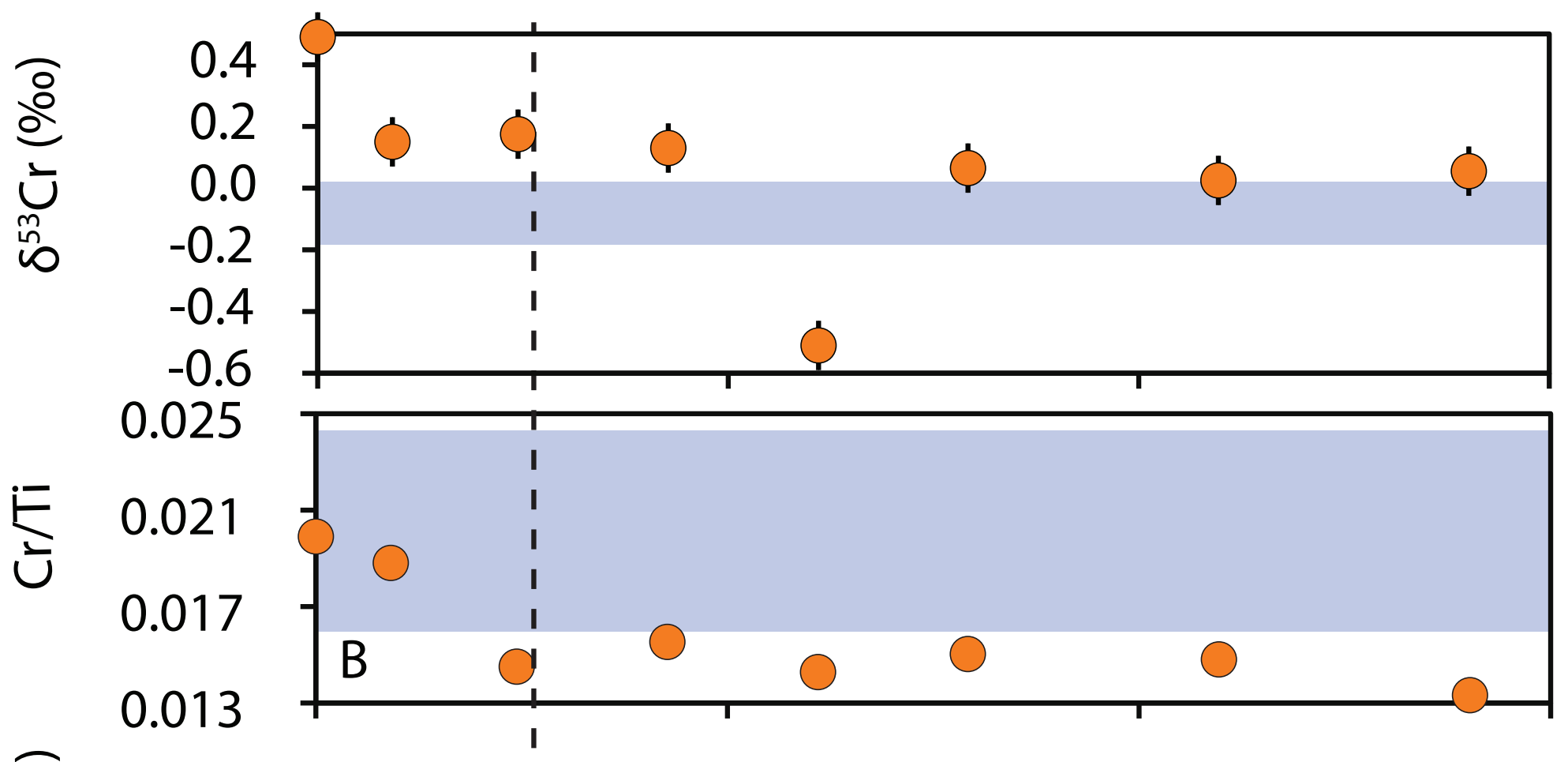

$\sum^{0}$
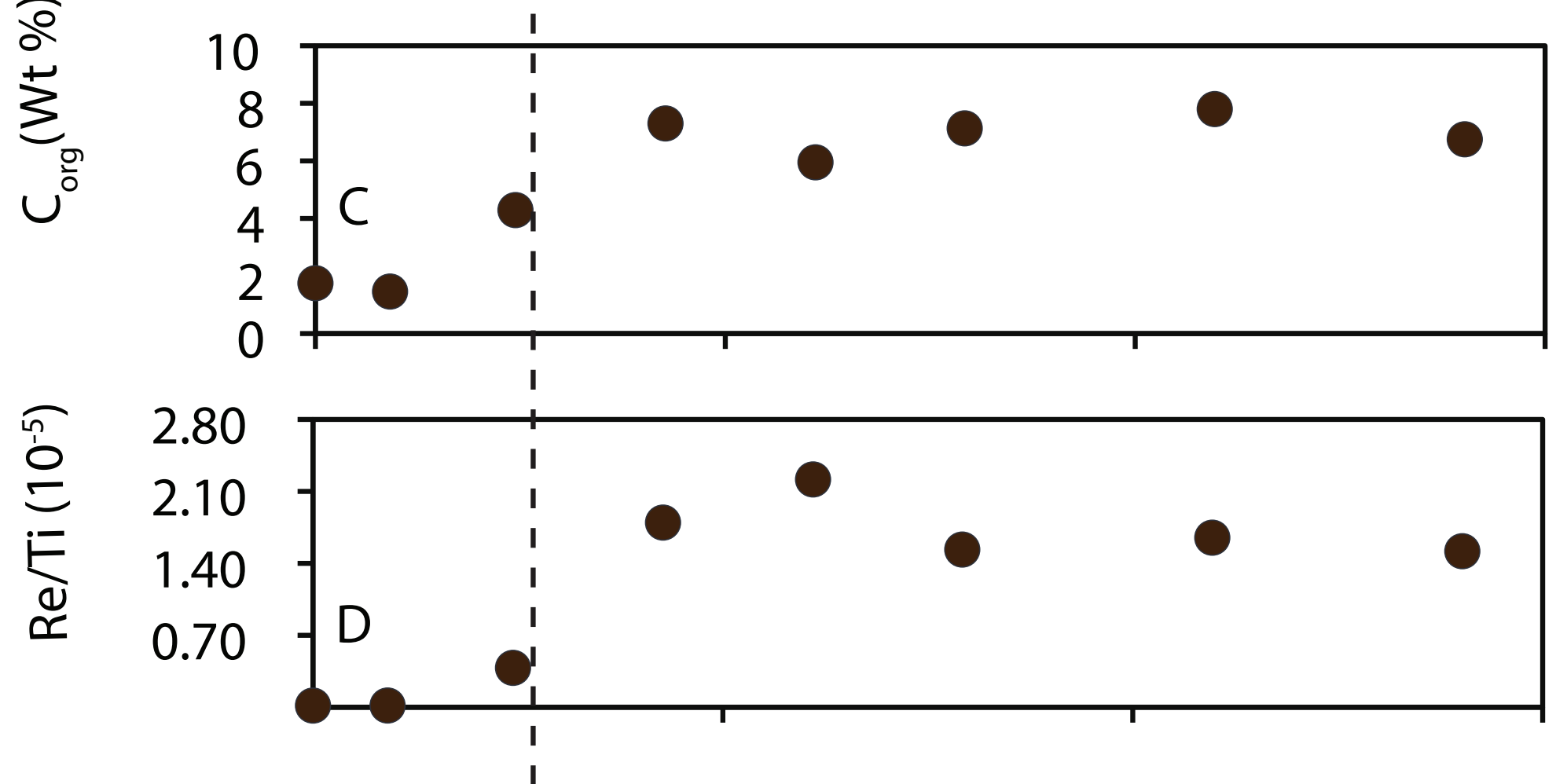

$\sum_{0}^{\infty}$

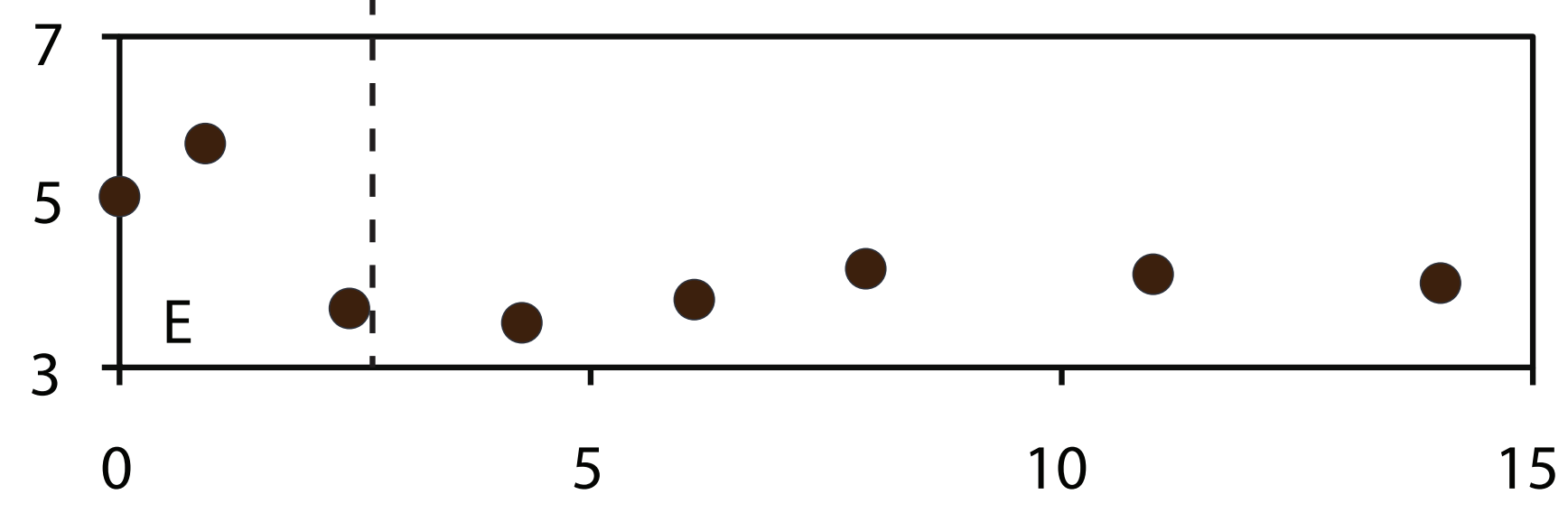

Distance from the surface $(\mathrm{m})$ 


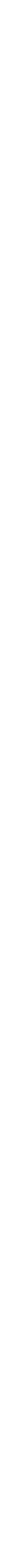

Figure 10

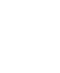




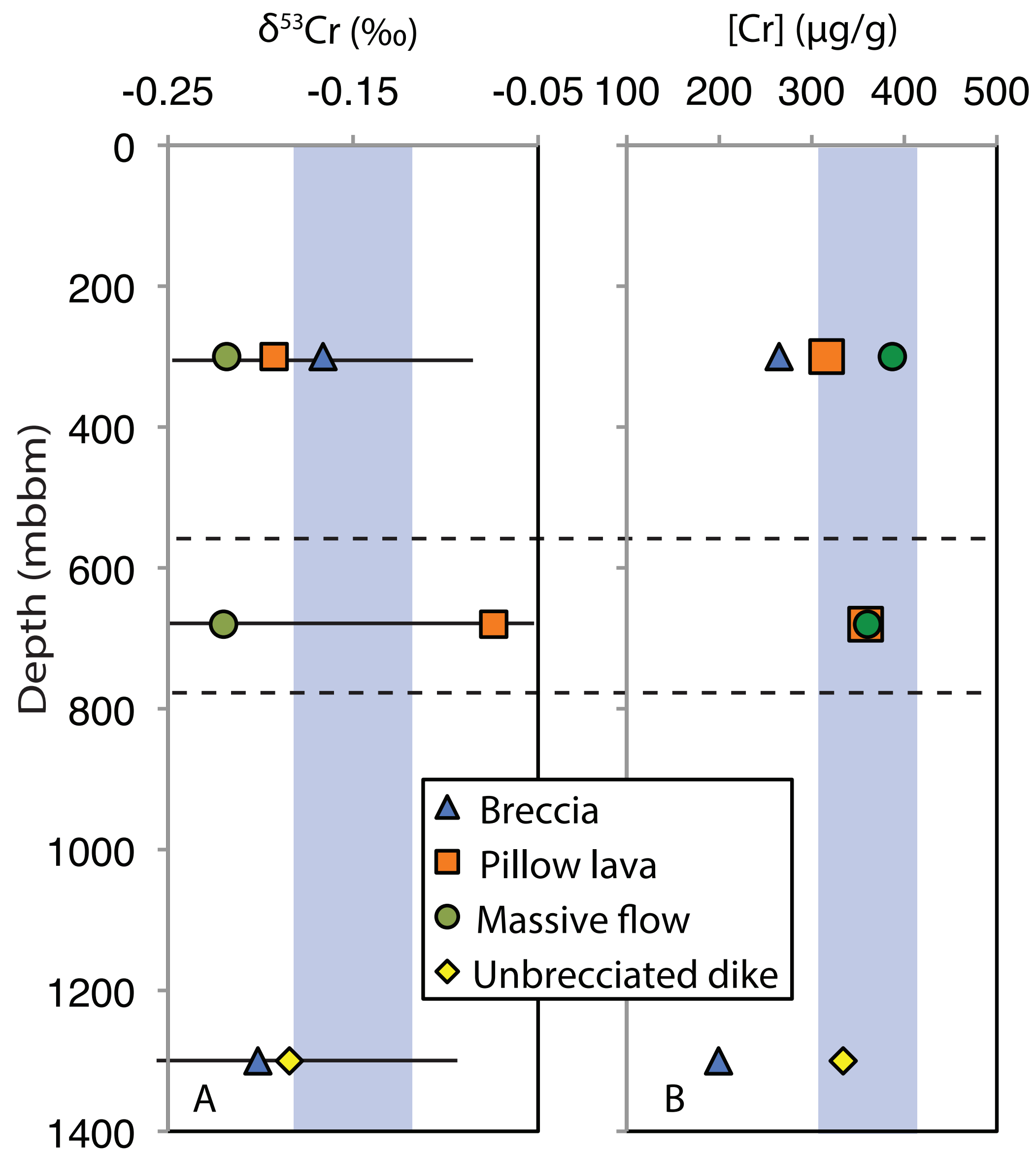




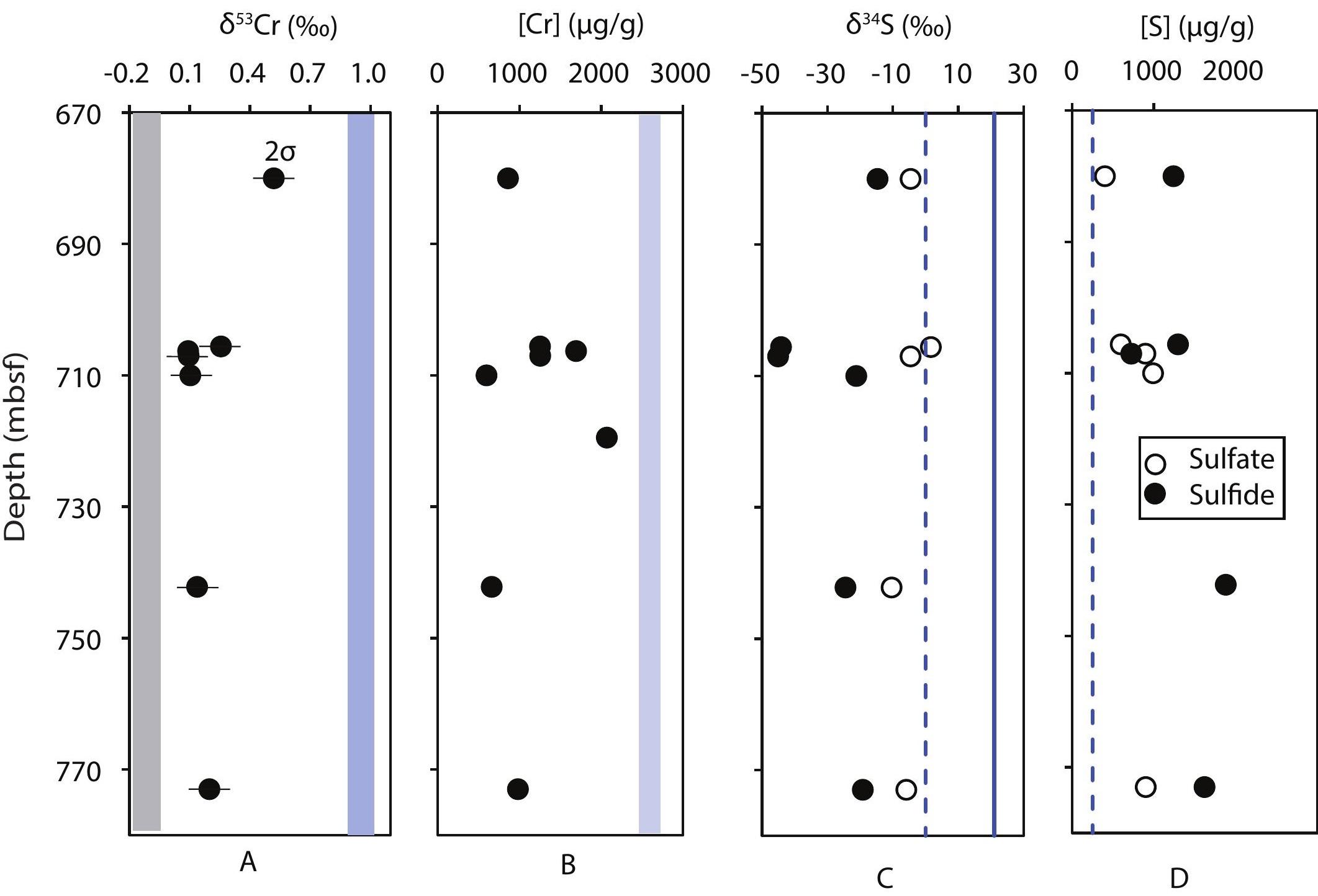

